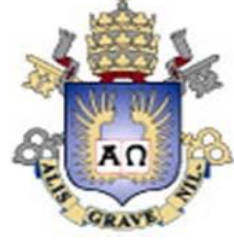

Naielly Lopes Marques

\title{
Um Modelo para Oferta de Certificados de Energia Renovável na Blockchain sob Incerteza \\ e Flexibilidade
}

Dissertação de Mestrado

Dissertação apresentada ao Programa de Pósgraduação em Administração de Empresas da PUCRio como requisito parcial para obtenção do grau de Mestre em Administração de Empresas.

Orientador: Prof. Luiz Eduardo Teixeira Brandão

Rio de Janeiro Janeiro de 2019 


\section{Pontifícia Universidade Catálica $_{\text {a }}$

Naielly Lopes Marques

\section{Um Modelo para Oferta de Certificados de Energia Renovável na Blockchain sob Incerteza \\ e Flexibilidade}

Dissertação apresentada como requisito parcial para obtenção do grau de Mestre pelo Programa de Pósgraduação em Administração de Empresas da PUC-Rio. Aprovada pela Comissão Examinadora abaixo assinada.

Prof. Luiz Eduardo Teixeira Brandão

Orientador

Departamento de Administração - PUC-Rio

Prof. Leonardo Lima Gomes

Departamento de Administração - PUC-Rio

Prof. Carlos de Lamare Bastian Pinto

Pesquisador Autônomo

Prof. Augusto Cesar Pinheiro da Silva Coordenador Setorial do Centro de Ciências Sociais - PUC- 
Todos os direitos reservados. É proibida a reprodução total ou parcial do trabalho sem autorização da universidade, do autor e do orientador.

\section{Naielly Lopes Marques}

Graduada em Administração de Empresas pela Universidade Veiga de Almeida (UVA) em 2016. Técnica em Segurança do Trabalho pelo Centro Federal de Educação Tecnológica Celso Suckow da Fonseca (CEFET) em 2014. Possui experiência no setor privado na área de Saúde e Segurança do Trabalho e tem atuado como pesquisadora pelo Núcleo de Pesquisa em Energia e Infraestrutura da PUC-Rio (NUPEI).

Ficha Catalográfica

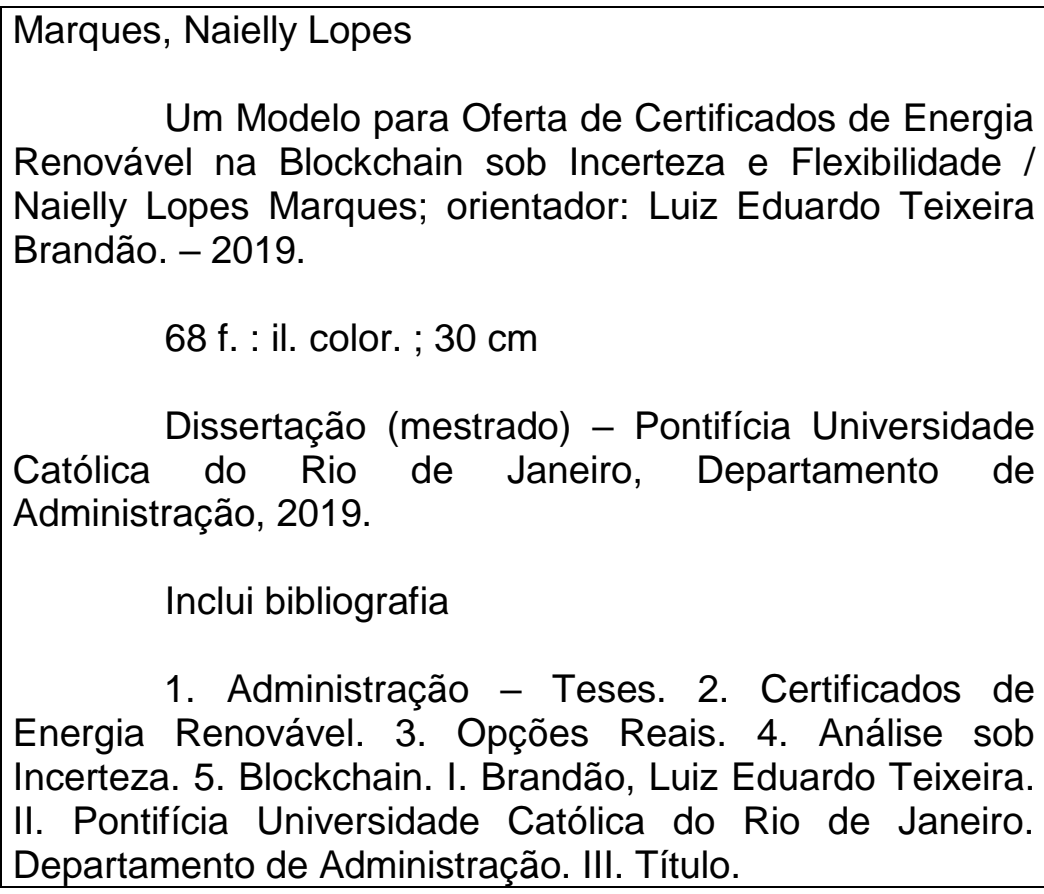

Um Modelo para Oferta de Certificados de Energia Renovável na Blockchain sob Incerteza e Flexibilidade / Naielly Lopes Marques; orientador: Luiz Eduardo Teixeira Brandão. - 2019.

68 f. : il. color. ; $30 \mathrm{~cm}$

Dissertação (mestrado) - Pontifícia Universidade Católica do Rio de Janeiro, Departamento de Administração, 2019.

Inclui bibliografia

1. Administração - Teses. 2. Certificados de Energia Renovável. 3. Opções Reais. 4. Análise sob Incerteza. 5. Blockchain. I. Brandão, Luiz Eduardo Teixeira. II. Pontifícia Universidade Católica do Rio de Janeiro. Departamento de Administração. III. Título. 


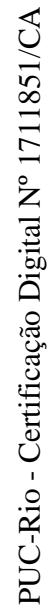

À minha família. 


\section{Agradecimentos}

Ao meu orientador, professor Luiz Eduardo Teixeira Brandão, pela dedicação, pela generosidade em compartilhar seu conhecimento e pelo permanente incentivo desde o início deste trabalho.

Ao professor Leonardo Lima Gomes, pelas contribuições ao trabalho e por todo o apoio que me forneceu durante o mestrado.

Ao professor Carlos de Lamare Bastian Pinto, pelo apoio durante este trabalho e por incentivar meu desenvolvimento no meio acadêmico.

Aos meus pais, Tânia Lopes Marques e Walace Heleno Marques Faria, pelo apoio incondicional, carinho, educação e ensinamentos ao longo da vida.

À minha irmã Nathally Lopes Marques, pelo apoio e compreensão durante este processo.

Aos professores da PUC-Rio, por compartilharem seus conhecimentos.

Às minhas amigas de mestrado, Alice Fucs, Cynthia Santos e Paloma Cainelli, que compartilharam comigo ótimos momentos ao longo desse período de estudo.

Aos amigos do NUPEI, pela convivência e troca de experiências.

Ao CNPq e à PUC-Rio, pelos auxílios concedidos, sem os quais este trabalho não poderia ter sido realizado. 


\section{Resumo}

Marques, Naielly Lopes; Brandão, Luiz Eduardo Teixeira. Um Modelo para Oferta de Certificados de Energia Renovável na Blockchain sob Incerteza e Flexibilidade. Rio de Janeiro, 2019. 68p. Dissertação de Mestrado - Departamento de Administração, Pontifícia Universidade Católica do Rio de Janeiro.

A redução da poluição e das emissões de gases de efeito estufa tem sido o foco de um grande esforço global. Nesse contexto, Certificados de Energia Renovável (RECs) são de grande importância para incentivar mudanças na matriz energética, visando à adoção de práticas sustentáveis. Dado o crescimento deste mercado e as características dos RECs, uma das potenciais ferramentas impulsionadoras da sua adoção é o protocolo de rede blockchain. Nesta pesquisa, analisamos três modelos autônomos de emissão e venda na blockchain de tokens baseados em RECs em condições de incerteza para um gerador de energia renovável. Nos três modelos, o gerador tem a opção de investir agora ou daqui a um ano para ter o direito de emitir RECs e ofertá-los através de leilões de venda trimestrais. No primeiro, assumimos que o preço do token é fixo, seguindo o conceito de uma stable coin. No segundo, consideramos que o preço segue uma função inversa da demanda sujeita a choques estocásticos. Finalmente, no terceiro, a demanda por RECs é incerta e busca-se maximizar o lucro do gerador. Realizamos uma aplicação numérica para verificarmos a validade dos modelos e concluímos, considerando os parâmetros adotados, que o gerador deverá investir no segundo modelo, pois foi o que apresentou maior VPL (R\$ 60.992,70). Contudo, se a volatilidade da demanda for inferior a 20,00\%, o modelo ótimo para o gerador é o primeiro modelo. A principal contribuição deste trabalho é analisar a dinâmica do desempenho de produtos digitais sob incerteza.

\section{Palavras- chave}

Certificados de Energia Renovável; Opções reais; Análise sob Incerteza; Blockchain. 


\section{Abstract}

Marques, Naielly Lopes; Brandão, Luiz Eduardo Teixeira (Advisor). A Blockchain based Model for the Offer of Renewable Energy Certificates under Uncertainty and Flexibility. Rio de Janeiro, 2019. 68p. Dissertação de Mestrado - Departamento de Administração, Pontifícia Universidade Católica do Rio de Janeiro.

Reducing pollution and greenhouse gas emissions has been the focus of a major global effort. In this context, Renewable Energy Certificates (RECs) are important as they provide incentives for changes in the energy matrix, towards the adoption of sustainable practices. Given the growth of this market and the characteristics of RECs, one of the potential drivers of their adoption is the blockchain network protocol. In this research, we analyze three autonomous models for issuing and selling in the blockchain of REC based tokens for the renewable energy generator. In all three models, the generator has the option to invest now or in one year for the right to issue RECs and offer them through quarterly sales auctions. In the first model, we assume that the token price is fixed following a stable coin concept. In the second model, we consider that the price follows an inverse demand function subject to stochastic shocks. Finally, in the third model, the demand for RECs is uncertain and the purpose is to maximize the generator's profit. Through a numerical application, we verify the validity of the models and conclude, considering the parameters adopted, that the generator should invest in the second model, since it was the one with the highest NPV $(\mathrm{R} \$ 60,992.70)$. However, if the demand volatility is less than $20.00 \%$, the optimal model for the generator is the first model. The main contribution of this work is to analyze the performance dynamics of digital products under uncertainty.

\section{Keywords}

Renewable Energy Certificates; Real options; Analysis under Uncertainty; Blockchain. 


\section{Sumário}

1 Introdução

2 Referencial Teórico 14

2.1. Esquemas de Apoio à Energia Renovável 14

$\begin{array}{ll}\text { 2.2. Blockchain } & 17\end{array}$

2.3. Teoria das Opções Reais 19

2.3.1. Aplicações de Opções Reais em Energia Renovável 21

2.4. Teoria dos Leilões 24

3 Certificados de Energia Renovável $\quad 27$

4 Modelagem $\quad 29$

4.1. Primeiro Modelo 30

4.2. Segundo Modelo 35

4.3. Terceiro Modelo 38

5 Exemplo Numérico e Resultados 41

5.1. Análise dos Resultados do Primeiro Modelo 41

5.1.1. Análises de Sensibilidade 43

5.2. Análise dos Resultados do Segundo Modelo 46

5.2.1. Análises de Sensibilidade 48

5.3. Análise dos Resultados do Terceiro Modelo 50

5.3.1. Análises de Sensibilidade 53

5.4. Análise Comparativa dos Modelos 55

6 Conclusões $\quad 57$

7 Referências bibliográficas $\quad 59$

8 Apêndice $\quad 64$ 


\section{Lista de figuras}

Figura 1 - Esquema Geral de Leilões de Venda 29

Figura 2 - Estrutura Binomial CRR 33

Figura 3 - Adiamento do Investimento no Primeiro Modelo 35

Figura 4 - Adiamento do Investimento no Segundo Modelo 38

Figura 5 - Política de Decisão no Primeiro Modelo 43

Figura 6 - Análise de Sensibilidade da Volatilidade no Primeiro Modelo 44

Figura 7 - Opção Real Tradicional $\quad 44$

Figura 8 - Análise de Sensibilidade do Custo Marginal Unitário de Entrada no Primeiro Modelo 45

Figura 9 - Política de Decisão no Segundo Modelo 48

Figura 10 - Análise de Sensibilidade da Volatilidade no Segundo Modelo

Figura 11 - Análise de Sensibilidade do Custo Marginal Unitário de Entrada no Segundo Modelo 50

Figura 12 - Política de Decisão no Terceiro Modelo 53

Figura 13 - Análise de Sensibilidade da Volatilidade no Terceiro Modelo

Figura 14 - Análise de Sensibilidade do Custo Marginal Unitário de Entrada no Terceiro Modelo

Figura A.1 - Árvore Binomial do Primeiro Modelo 64

Figura A.2 - Árvore Binomial do Primeiro Modelo com Opção de Adiamento 65

Figura A.3 - Árvore Binomial do Segundo Modelo 66

Figura A.4 - Árvore Binomial do Segundo Modelo com Opção de Adiamento

Figura A.5 - Árvore Binomial do Terceiro Modelo 68

Figura A.6 - Árvore Binomial do Terceiro Modelo com Opção de Adiamento 


\section{Lista de tabelas}

Tabela 1 - Parâmetros Comuns aos Três Modelos

Tabela 2 - Equivalência entre Valores Presentes no Primeiro Modelo

Tabela 3 - Projeção da Demanda

Tabela 4 - Equivalência entre Valores Presentes no Segundo

Modelo

Tabela 5 - Projeção do Choque

Tabela 6 - Demanda Esperada no Caso Base

Tabela 7 - Equivalência entre Valores Presentes no Terceiro Modelo

Tabela 8 - Demanda Esperada no Caso de Adiamento

Tabela 9 - Sensibilidade do Custo Marginal Unitário na Escolha do Modelo Ótimo

Tabela 10 - Sensibilidade da Volatilidade na Escolha do Modelo Ótimo 


\section{Introdução}

A emissão de gases de efeito estufa tem sido um dos principais fatores que contribuem para o aquecimento global, e o foco de preocupação mundial (Lellis, 2007). A fim de reduzir as emissões de $\mathrm{CO}_{2}$ geradas pela produção de eletricidade, uma das principais fontes de gases de efeito estufa, grandes corporações estão investindo cada vez mais em fontes de energia limpa. No entanto, essas iniciativas exigem grandes investimentos de capital em fontes de energia renovável, que muitas vezes se encontram fora do alcance ou da atividade fim de algumas empresas. Uma das alternativas, nesse caso, é continuar recebendo a energia de fontes tradicionais e adquirir Certificados de Energia Renovável (Renewable Energy Certificates - RECs) em volume equivalente ao consumo da empresa, alcançando assim seu balanço de energia limpa.

Os Certificados de Energia Renovável foram propostos em 1996 como instrumentos negociáveis baseados no mercado, emitidos quando um megawatthora (MWh) de eletricidade é gerado a partir de uma fonte de energia renovável e entregue à rede elétrica (Abragel, 2018). Os RECs foram projetados para fomentar a produção de energia renovável, fornecendo uma fonte adicional de receita para esses geradores. Estes certificados podem ser transferidos, comprados, vendidos, retirados ou utilizados pelo titular para alegar que utilizou energia renovável.

Atualmente, o ciclo de certificação funciona da seguinte forma: uma empresa que deseja ser emissora de RECs deve aderir a um código e passar por uma auditoria documental pelo emissor local (Instituto Totum, 2018). Com todos os documentos em conformidade e a auditoria concluída, a empresa paga as taxas do programa e registra-se na plataforma, podendo, a partir disso, emitir e transferir RECs. Nesse sentido, os RECs ajudam a superar diversas barreiras referentes à compra e venda de atributos de energia renovável associados à eletricidade, como: o acesso à transmissão e políticas de preços, intermitência de recursos e a falta de liquidez do mercado (Wingate e Holt, 2004). 
Os mercados de RECs têm se expandido rapidamente e já possuem liquidez significativa em todo o mundo e, cada vez mais, os países estão se preocupando e investindo em energia renovável. Apesar disso, ainda questiona-se: como é possível promover ainda mais esse mercado de uma maneira que seja prática para todos os seus stakeholders? Parte da resposta pode ser encontrada no uso de inovações tecnológicas, como a Distributed Ledger Technology (DLT), que permite a tokenização e distribuição barata de RECs em todo o mundo.

A DLT também permite a criação de moedas digitais, que além de ser uma nova forma de pagamento, como observado por Extance (2015), Maftei (2014), Negurita (2014), Little (2014), Bryans (2014), Hurlburt e Bojanova (2014), e Brito e Castillo (2013), podem promover agilidade nas transações, reduzir ou eliminar a burocracia nos meios de pagamento e aumentar a segurança e a transparência das transações. Em particular, as blockchains, que são um tipo de DLT, dependem de um sistema de contabilidade pública distribuída, dividida em blocos, onde cada bloco é criptograficamente conectado ao bloco anterior, formando uma cadeia de blocos, ou uma blockchain. $\mathrm{O}$ fato de as informações em cada bloco serem públicas e imutáveis permite inúmeras novas aplicações na indústria baseadas no protocolo blockchain. Programas, também conhecidos como smartcontracts, podem ser desenvolvidos para serem executados em blockchains, com todos os benefícios que essa tecnologia oferece, como transparência e segurança.

Nesse estudo, propomos três modelos distintos para o desenvolvimento de tokens baseados em RECs, que podem ser automatizados e incluídos em um smartcontract na blockchain. Nos três modelos propostos, o gerador de energia renovável, interessado em ofertar RECs, tem a opção de investir agora ou daqui a um ano para ter o direito de emitir RECs e vendê-los posteriormente através de leilões de venda trimestrais promovidos automaticamente pelo próprio protocolo inteligente.

No primeiro modelo, consideramos que a volatilidade dos preços e a curva inflacionária são controladas por ajustes na oferta de RECs, visto que a série histórica de transações diárias de RECs é extremamente volátil. Nesse caso, assumimos que o preço de venda do token é fixo em todos os trimestres, seguindo o conceito de uma stable coin. 
Por outro lado, no segundo modelo, consideramos que a demanda por RECs é determinística e que possui um crescimento percentual em cada trimestre. Ademais, neste protocolo, o preço unitário do token varia a cada trimestre e é uma função de demanda inversa sujeita a choques contínuos estocásticos.

Por fim, no terceiro modelo, a finalidade é maximizar o lucro do gerador de energia renovável, através da escolha da demanda ótima. Neste caso, a demanda por RECs é uma variável estocástica e o preço de venda do token, assim como no segundo modelo, é uma função de demanda inversa.

Portanto, o objetivo deste estudo é avaliar, a partir desses modelos propostos, qual o modelo ótimo do ponto de vista do gerador de energia renovável. Para isso, utilizamos a abordagem de opções reais, que possibilitou avaliar a opção de adiamento presente em cada modelo e analisar a tomada de decisão sob incerteza do gerador.

Diante disso, consideramos que, ao propor três protocolos inteligentes de emissão e venda de RECs, este estudo contribui com a ampliação da literatura referente a aplicações da tecnologia blockchain no mercado de renováveis e é relevante, pois propõe três DAOs (Decentralized Autonomous Organizations) para emissão e venda de tokens de RECs. Ademais, esta pesquisa evidencia que métodos simples de precificação de opções reais podem auxiliar a tomada de decisão quando há incerteza e flexibilidade, fazendo com que as oportunidades de investimento sejam melhor avaliadas.

Este estudo está estruturado da seguinte forma: após esta introdução, no Capítulo 2, revisamos a literatura sobre esquemas de apoio à energia renovável, a tecnologia blockchain, a Teoria das Opções Reais e a Teoria dos Leilões. No Capítulo 3, discutimos como funcionam os Certificados de Energia Renovável e, no Capítulo 4, propomos os três modelos para o desenvolvimento de um token baseado em RECs. No Capítulo 5, analisamos os resultados e comparamos os modelos propostos. Por fim, no Capítulo 6, apresentamos as conclusões deste estudo e as sugestões para pesquisas futuras. 


\section{2 Referencial Teórico}

Neste capítulo será apresentado o referencial teórico utilizado na construção dos três protocolos autônomos, baseados na tecnologia blockchain, para emissão e venda de RECs. Este capítulo está dividido em quatro temas principais: esquemas de apoio à energia renovável, blockchain, Teoria das Opções Reais e Teoria dos Leilões. Será dada uma maior ênfase ao subcapítulo de Opções Reais, pois é o foco principal desse estudo.

\section{1.}

\section{Esquemas de Apoio à Energia Renovável}

A introdução de fontes de energia renovável na matriz de geração de eletricidade tem o potencial de reduzir as emissões do setor de energia, bem como a dependência dos países em relação ao petróleo importado (Fagiani, Barquín e Harkvoort, 2013). Segundo os autores, as preocupações com as mudanças climáticas e os preços altamente voláteis do petróleo atraíram o interesse dos governos em apoiar investimentos em energia renovável. Essa preocupação, que é mundial, foi inclusive incluída na nova Encíclica do Papa Francisco, Laudato Si, "Louvado seja", que aborda as preocupações que todos devemos ter com o meio ambiente de forma a atingir o objetivo de um desenvolvimento sustentável (Francis, 2016).

Mitchell, Bauknecht e Connor (2006) afirmam que a União Europeia é particularmente rica em variações de diferentes mecanismos de entrega para aumentar o uso de energia renovável. Neste artigo, os autores analisam a obrigação de renováveis da Inglaterra, do País de Gales e da Alemanha, para verificar como cada política auxilia na redução dos riscos de preço, volume e balanceamento dos geradores. Os resultados mostram que um sistema feed-in é mais propenso a fornecer essa redução de risco, visto que este mecanismo é utilizado como uma política pública destinada a acelerar o investimento em 
tecnologias de atributos renováveis através da oferta de contratos de longo prazo aos produtores de energias renováveis.

Butler e Neuhoff (2008) também comparam esquemas de suporte para implantação de energia renovável baseada no mercado do Reino Unido e da Alemanha. Os autores concluem que, embora, em teoria, os sistemas do Reino Unido apresentem menores custos, a tarifa feed-in alemã gerenciou preços mais baratos pagos pela energia eólica e obteve maior competição.

A fim de aumentar a proporção de suprimento de eletricidade obtida de fontes renováveis, muitos países introduziram sistemas de Certificados Verdes Negociáveis (Tradable Green Certificates - TGCs), que garantem que as metas renováveis sejam cumpridas economicamente e eliminam a necessidade de os governos fornecerem subsídios diretos para as energias renováveis, como as tarifas feed-in (Amundsen e Nese, 2009). Segundo Currier (2013), esses sistemas são esquemas de subsídio destinados a promover a geração de eletricidade a partir de fontes de energia renovável e seu principal instrumento de política regulatória é o "percentual obrigatório", que determina a porcentagem da produção total de eletricidade que deve ser obtida de fontes renováveis.

Morthorst (2000) afirma que um mercado verde permitirá que as tecnologias renováveis sejam parcialmente compensadas economicamente pelos benefícios ambientais gerados em comparação com a produção de energia convencional. Por outro lado, de acordo com Fristrup (2003), existem alguns obstáculos relacionados ao uso de TGCs como parte da política energética, tais como: gerenciar a coexistência de vários tipos de fornecedores de fontes de energia renováveis com apenas uma ferramenta política.

Tamás, Bade Shrestha e Zhou (2010) comparam os regimes de tarifas feedin (FIT) e TGC no mercado liberalizado de eletricidade. Os autores concluem que, se os mercados fossem perfeitamente competitivos, a tarifa de alimentação e o preço do certificado seriam os mesmos. Por outro lado, se os mercados fossem imperfeitos, seriam geralmente diferentes. Além disso, eles comparam o bemestar social dos dois programas numericamente, usando dados do mercado do Reino Unido. Os resultados mostram que o bem-estar social sob TGC é consistentemente maior do que o FIT para uma ampla gama de valores dos parâmetros. 
Fagiani, Barquín e Harkvoort (2013) analisam os efeitos da aversão ao risco dos investidores sobre o desempenho de dois diferentes esquemas de apoio: um mecanismo FIT, no qual os investidores recebem um preço fixo por cada MWh de eletricidade produzida; e um sistema de mercado de certificados, onde o regulador define o nível de penetração no mercado de energia renovável e estabelece um preço para cada MWh de eletricidade produzida. Os resultados indicam que, embora um mecanismo FIT possa obter melhores resultados do que um mercado de certificados, seu desempenho é estritamente dependente das escolhas dos reguladores. Por outro lado, um sistema de certificação de mercado, como o sistema de RECs, permite obter o nível desejado de participação no mercado de energia renovável com boa relação custo-benefício, desde que a aversão ao risco dos investidores seja moderada.

Segundo Wingate e Holt (2004), os RECs, também conhecidos como etiquetas verdes, certificados verdes, créditos de energia renovável e TGCs, representam o conjunto separável de atributos não energéticos (ambientais, econômicos e sociais) associados à geração de eletricidade renovável. Além disso, os autores acreditam que o REC é a moeda dos mercados de energia renovável (mercados de conformidade e voluntários) que permite acessar, alocar e reivindicar o uso de geração renovável em uma rede compartilhada. Nessa perspectiva, esse mecanismo serve como ferramenta para atingir as metas corporativas de relatórios de gases de efeito estufa, bem como mandatos de políticas estaduais sob os padrões do Portfólio de Energia Renovável.

Bertoldi e Huld (2006) afirmam que os recentes avanços na tecnologia de informação e comunicação, como a Internet e a medição inteligente, abriram novas possibilidades para melhorar a eficiência energética e aumentar a utilização de fontes de energia renovável, permitindo aumentar a quantidade de emissões e transações de RECs. Seguindo essa mesma lógica, acredita-se que novas tecnologias, como a blockchain, também poderão trazer muitos benefícios ao mercado de energia renovável. 


\section{2. \\ Blockchain}

A transparência é crucial nos mercados de energia renovável uma vez que a compra de energia verde, tanto o quilowatt-hora em si quanto os seus atributos limpos, acontece de forma diferente de outros produtos. Os compradores não conseguem controlar ou observar como suas instalações são realmente alimentadas. Desta forma, aqueles que querem alimentar suas instalações com energias renováveis dependem de uma ferramenta de contabilidade conhecida como RECs, onde se podem comprovar as compras ecológicas, permitindo uma verificação confiável.

Os RECs fornecem detalhes sobre cada MWh de geração de energia renovável, incluindo como, onde, quando e por quem o $\mathrm{MWh}$ se originou. Atualmente, operadores de sistema e reguladores usam um registro em seu sistema elétrico para rastrear os detalhes, propriedade e status de cada REC.

Embora os RECs tenham ajudado a aprimorar a transparência nos mercados de energia renovável, essas melhorias ainda são insuficientes para atender as crescentes necessidades de geradores e compradores de energia renovável. Por exemplo, desenvolvedores e compradores precisam passar por um processo excessivamente dispendioso que difere de mercado para mercado e depende de plataformas tecnológicas obsoletas simplesmente para obter a prova de geração e compra de energia verde.

Diante disso, a participação no mercado é geralmente limitada a empresas com equipes sofisticadas e empresas de energia com metas de portfólio de energia renovável exigidas pela regulamentação. Para desbloquear o acesso e aumentar a participação no mercado, a compra e venda de energia renovável precisa ser menos burocrática. Nessa perspectiva, acredita-se que uma forma de eliminar as atuais barreiras desse mercado é apostar numa nova tecnologia global disruptiva e de rápido alcance, como a blockchain, que poderá promover agilidade nas transações, reduzir ou eliminar a burocracia nos meios de pagamento e aumentar a segurança e a transparência das operações.

O protocolo blockchain foi proposto pela primeira vez por Nakamoto (2008) e é a base sobre a qual o bitcoin foi criado. Esse protocolo é um tipo de 
Distributed Ledger Technology (DLT), que como o nome sugere, é um livro razão público onde as transações são agrupadas em blocos.

Nesse protocolo, os usuários assinam criptograficamente suas transações e enviam-nas para a rede em que entidades conhecidas como mineradores validam todas as transações, confirmando que o usuário que gastou o dinheiro tem dinheiro para gastar, bem como a autenticidade do usuário. Então, os mineradores escolhem quais transações incluir em seu próprio bloco e a ordem em que serão incluídas. Como apenas um bloco pode ser adicionado por vez, um mecanismo conhecido como proof of work, que exige um significativo dispêndio de energia e esforço computacional, é utilizado para decidir qual dos mineradores terá o direito de adicionar seu bloco ao blockchain.

No caso do blockchain do bitcoin, cada vez que um minerador consegue adicionar seu bloco, ele recebe uma quantidade de bitcoins em recompensa. Depois que o bloco é processado, ele é enviado para a rede, onde os usuários que possuem cópias de todo o blockchain e validam cada bloco de entrada são conhecidos como nós. É esse procedimento que permite que um ledger distribuído funcione sem nenhuma confiança necessária entre as partes envolvidas.

Alguns estudos já propõem a aplicação desta tecnologia aos mercados de energia renovável. Mihaylov et al. (2014), por exemplo, desenvolvem uma nova moeda digital descentralizada, chamada NRGcoin. Os autores acreditam que a principal contribuição desse novo mecanismo é converter energia renovável produzida localmente diretamente em NRGcoins, independentemente de seu valor no mercado. Além disso, os autores propõem um novo paradigma comercial para compra e venda de energia verde na rede blockchain, criando um ecossistema microeconômico que permite à negociação de energia renovável produzida localmente a preços competitivos.

Por outro lado, Mengelkamp et al. (2018) se baseiam numa blockchain privada para desenvolver uma plataforma de mercado descentralizada, visando negociar a geração de energia renovável local sem a necessidade de um intermediário. Como os mercados locais de energia renovável permitem que os consumidores comercializem a geração produzida localmente diretamente em sua comunidade, os autores acreditam que a blockchain é a principal tecnologia de informação e comunicação para esse mercado. 
Uma abordagem interessante é proposta por Castellanos, Coll-Mayor e Notholt (2017), na qual a blockchain do Ethereum e os contratos inteligentes são usados para que prosumers, isto é, consumidores proativos com recursos de energia distribuída possam vender garantias de origem (GoOs) para subsidiar os produtores de energia renovável. Nesse sentido, os autores apresentam duas estratégias: a primeira baseada no preço médio de GoOs em 2014 e a segunda baseada na diferença de preços entre a energia cinza e a verde. Os resultados desse estudo mostram que é mais vantajoso para os prosumers seguir a segunda estratégia.

Araki et al. (2018) propõem um modelo monopolista de lançamento de criptomoedas baseadas em RECs que garante o controle da curva inflacionária da moeda a partir de ajustes em sua oferta. Nesse estudo, os autores utilizam a teoria microeconômica e a teoria de opções reais como os principais pilares para o desenvolvimento do modelo e concluem que este é bastante útil para a comercialização bem-sucedida de RECs tanto para o ofertante quanto para o consumidor final devido às vantagens competitivas oferecidas pela tecnologia blockchain.

Apesar de existirem algumas aplicações da tecnologia no mercado de renováveis, não foram encontrados na literatura estudos que analisam a tomada de decisão sob incerteza do gerador de energia renovável perante três organizações distintas e autônomas (DAOs - Decentralized Autonomous Organizations) cujas regras de emissão e venda de RECs são especificadas em smartcontracts, que são executados e validados pela blockchain.

\section{3.}

\section{Teoria das Opções Reais}

A teoria de opções reais surgiu da necessidade de levar em conta a flexibilidade gerencial na avaliação de projetos, que não é contemplada por técnicas tradicionais, como o método de Fluxo de Caixa Descontado - FCD (Copeland e Tufano, 2004). Essa nova abordagem adapta os modelos de precificação de opções financeiras desenvolvidos por Black e Scholes (1973) e Merton (1973), permitindo o tratamento do investimento sob incerteza e flexibilidade. 
Em resumo, uma opção financeira é um derivativo que dá ao detentor o direito, mas não a obrigação, de comprar ou vender o ativo subjacente, que pode ser uma ação, índice ou contrato futuro, por um preço pré-determinado, conhecido como preço de exercício. Segundo Hull (2009), quando o direito é comprar o ativo, a opção é chamada de call e, quando o direito é vender o ativo, a opção é chamada de put. Além disso, se a opção só puder ser exercida em sua data de vencimento, ela será considerada uma opção europeia. Mas, se a opção puder ser exercida a qualquer momento até sua data de vencimento, então é uma opção americana.

No caso de opções reais, o ativo subjacente pode ser um investimento, um projeto ou uma aquisição de ativos reais. O preço de exercício da opção é dado pelo valor investido, se a opção for uma call, ou pelo valor recebido, se a opção for uma put. Nesta perspectiva, enquanto as opções financeiras têm um contrato detalhado entre as partes envolvidas, as opções reais são caracterizadas como estratégias de investimento. Isso ocorre porque a opção financeira oferece o direito de comprar ou vender um ativo e a opção real representa as alternativas que uma empresa possui dentro de um projeto.

Triantis (2005) afirma que, ao utilizar o método das opções reais, os gestores de uma empresa são capazes de responder às mudanças no mercado mais facilmente, e até mesmo de serem proativos e gerar novas flexibilidades nos projetos. Portanto, a teoria das opções reais é uma ferramenta que permite avaliar empresas ou projetos que apresentam flexibilidade e incerteza gerencial.

Segundo Trigeorgis (1996), existem diferentes tipos de opções reais, como: a opção de paralisação temporária, de troca de uso, de conversão e compostas. Mas, os principais são:

a) Opção de Abandono: é considerada uma opção de venda americana, uma vez que a administração pode exercer o direito de liquidar seus ativos a qualquer momento. Em alguns casos, a descontinuidade do projeto e a venda dos ativos no mercado secundário é uma estratégia mais vantajosa do que os fluxos de caixa futuros que o projeto pode gerar.

b) Opção de Expansão: caracteriza-se como opção de compra americana, pois considera a possibilidade de expansão do projeto em momentos favoráveis. A expansão é feita a partir de novos investimentos e, portanto, 
o preço de exercício dessa opção deve ser igual ao valor presente dos investimentos adicionais totais.

c) Opção de Contração: é análoga a opção de venda americana e é usada quando o desempenho esperado de um projeto não é alcançado. Neste caso, o projeto não está completamente abandonado, mas sua escala de operação é reduzida. Portanto, o preço de exercício desta opção deve ser igual ao valor presente das despesas futuras salvas.

d) Opção de Adiamento: equivale a uma opção de compra americana, já que esperar por mais informações sobre o mercado pode tornar o projeto mais valioso.

e) Opção de Interrupção: é modelada como uma opção de venda americana, onde é possível parar antes do projeto atingir sua fase operacional. Esse tipo de opção é comum em projetos de grande porte, como P\&D e financiamentos de capital de risco, nos quais o investimento é feito em diversas etapas.

Myers (1977) é creditado como um dos primeiros autores a usar opções reais para determinar o valor de ter flexibilidade e capacidade de investimento no futuro. Ele mostrou que as empresas que têm um alto risco de dívida perderão oportunidades valiosas de investimento, enquanto as empresas que têm baixo risco de dívida poderão aproveitar as oportunidades futuras de investimento. Mcdonald e Siegel (1985), Titman (1985), Majd e Pindyck (1987) e Triantis e Hodder (1990) desenvolveram ainda mais o campo, fornecendo soluções para aplicações particulares. Alguns anos depois, Dixit e Pindyck (1994) e Trigeorgis (1996) sintetizaram os principais conceitos e as possíveis aplicações dessa metodologia.

\subsection{1.}

\section{Aplicações de Opções Reais em Energia Renovável}

Uma vez que o setor elétrico iniciou um processo de desregulamentação, com alto nível de competitividade e aumento da incerteza do mercado, técnicas tradicionais de avaliação de projetos tornaram-se insuficientes para lidar adequadamente com esses fatores adicionais de risco e incerteza (Fernandes, 
Cunha e Ferreira, 2011). Nesse sentido, o uso de técnicas de avaliação mais sofisticadas, como a abordagem de opções reais, agora é necessário para avaliar projetos de investimento no setor de energia.

Embora a literatura apresente várias aplicações de opções reais na avaliação de tecnologias e políticas de geração de energia elétrica, o uso desta metodologia em problemas relacionados à energia renovável é recente. Sob a perspectiva da análise de opções reais, Lee (2011) avalia as oportunidades de investimento em energia renovável, mostrando que este método é eficaz ao quantificar como a incerteza do planejamento de investimento influencia o desenvolvimento de energia renovável. Os resultados reafirmam que o valor do desenvolvimento de energia renovável aumenta à medida que aumentam o preço subjacente, o tempo até o vencimento, a taxa livre de risco e a volatilidade. Mas, diminui à medida que o preço de exercício aumenta.

Fontoura, Brandão e Gomes (2015) avaliam a viabilidade de converter um projeto de usina de biomassa com base em capim elefante em uma biorrefinaria, investindo em uma unidade de produção de carvão vegetal e/ou em uma usina de etanol de segunda geração, que representam as opções deste modelo. Através da adoção de um modelo híbrido de comercialização de energia, os autores concluem que os valores das opções são positivos e que o esquema proposto representa uma oportunidade viável e interessante para a diversificação sustentável da matriz energética.

Detert e Kotani (2013) investigam o momento ótimo de decisão para investimentos em fontes alternativas de energia em situações de incerteza usando a abordagem de opções reais. Para isso, eles analisam um estudo de caso na Mongólia, no qual a incerteza é o preço do carvão e, comparam a atratividade de continuar usando infraestruturas baseadas no carvão ou mudar para fontes de energia renovável.

Dias et al. (2011) estudam o caso de uma usina de cana-de-açúcar existente que produz tanto açúcar quanto etanol, que tem tanto a opção de expandir a produção quanto a opção de reformar sua antiga usina de cogeração. Esse trabalho foi desenvolvido devido à preocupação com a possível exaustão das reservas de combustíveis fósseis mundiais. Os resultados encontrados mostram que a reforma da usina de cogeração acrescenta um valor quase equivalente ao da flexibilidade de escolher o momento ideal para investir na expansão da usina, o que é 
significativo, considerando que a cogeração não é o negócio principal da usina de cana-de-açúcar.

Kim, Park e Kim (2017) propõem um modelo de opções reais que permite avaliar o investimento em energia renovável nos países em desenvolvimento. A principal preocupação dos autores é lidar com incertezas, como: a rápida mudança de tecnologias e as condições do governo anfitrião. Para testar a validade do modelo, os autores analisam o caso envolvendo um projeto hidrelétrico na Indonésia e concluem que a ferramenta proposta pode ajudar os países anfitriões e os investidores na avaliação de projetos de energia renovável com alta volatilidade e risco.

Oliveira et al. (2014) analisam a viabilidade de investir em uma unidade de cogeração de resíduo de biomassa e gás natural em uma planta industrial no Brasil, que tenha a flexibilidade de escolher entre um aumento na produção ou a geração de energia excedente para venda no mercado de curto prazo. A partir dos resultados encontrados, os autores concluem que o investimento é viável e que a opção agrega valor significativo ao projeto, o que sugere que os resíduos de biomassa podem ser uma alternativa energética sustentável.

Segundo Martínez-Ceseña e Mutale (2011), os custos e incertezas iniciais causados pela variabilidade da fonte de energia renovável, mudanças nos esquemas de suporte e outros fatores podem tornar pouco atraentes os projetos de energia renovável, quando estes são submetidos a avaliações financeiras tradicionais, como o método de fluxo de caixa descontado. Desta forma, os autores propõem uma metodologia, baseada na abordagem de opções reais, para o planejamento de projetos de geração de energia renovável. Utilizando um estudo de caso de energia hidrelétrica, os autores concluem que projetos planejados sob a metodologia proposta podem gerar maiores lucros.

Boomsma, Meade e Fleten (2012) analisam, através da metodologia de opções reais, o momento do investimento e a escolha de capacidade para projetos de energia renovável a partir de diferentes esquemas de apoio, como as tarifas feed-in e a negociação de certificados de energia renovável. Para testar o modelo proposto, os autores o aplicam em um estudo de caso nórdico baseado em energia eólica e concluem que as tarifas feed-in incentivam investimentos prévios, mas assim que o investimento for feito, o comércio de certificados de energia renovável cria incentivos para projetos maiores. 
De acordo com Fleten et al. (2016), os investidores de 214 projetos hidrelétricos na Noruega não se baseiam no modelo de opções reais. Diante dessa informação extraída por meio de entrevistas, os autores investigam como se comportam as decisões de investimento em energia renovável. Para isso, os autores avaliam os subsídios implícitos nas decisões dos investidores, através de dois modelos: o de opções reis e o de valor presente líquido. Com base na amostra analisada, os resultados mostram que o modelo de opções reais descreve significativamente melhor o comportamento dos investimentos em energia renovável.

Ritzenhofen e Spinler (2016) avaliam o impacto dos ajustes nos esquemas FIT, que são amplamente utilizados como instrumentos de política para promover investimentos em fontes de energia renováveis, verificando a relação entre o valor garantido pago pela quantidade de eletricidade produzida e a propensão a investir em fontes de energia renováveis. Nesse sentido, os autores propõem um modelo de mudança de regime para quantificar o impacto da incerteza regulatória induzida pelos reguladores considerando mudanças de um esquema FIT para um regime regulatório mais orientado para o mercado.

Kitzing et al. (2017) desenvolvem um modelo de opções reais para avaliar investimentos em energia eólica, considerando o momento ideal e a restrição de capacidade como parte da otimização. Os autores acreditam que esta abordagem se adequa bem para a comparação de diferentes esquemas de suporte, como: FIT, prêmios de alimentação e TGCs. Os resultados apontam que esquemas TGCs podem exigir margens de lucro até 3\% maiores do que os esquemas FIT, devido à maior variação nos lucros. Por outro lado, os esquemas FIT podem considerar tamanhos de projeto $15 \%$ menores. A análise desse trade-off deve ser considerada para que haja melhores projeções estratégicas do suporte renovável, bem como o desenvolvimento de esquemas de incentivo sob medida.

\section{4.}

\section{Teoria dos Leilões}

A Teoria dos Leilões, como observado por Smit e Trigeorgis (2006), pode ser vista como uma aplicação da teoria de desenho de mecanismos ou de jogos bayesianos, atuando como um esquema de compensação de mercado para 
controlar a oferta e a demanda. Dentro da classe de mecanismos de mercado que alocam recursos escassos, uma característica particular do leilão é que o processo de formação de preços é explícito, isto é, as regras que determinam o preço final são geralmente bem compreendidas por todas as partes envolvidas (Menezes e Monteiro, 2005).

Cassady (1967) apresenta os diversos usos práticos dos leilões, sendo um deles: proporcionar a venda de bens para os quais não existe um mercado estabelecido. Atualmente, os leilões também são amplamente utilizados nas compras governamentais, bem como, na identificação dos mercados de comercialização de eletricidade e licenças de poluição.

De acordo com as suas características, os leilões podem ser classificados em diversos tipos. Os principais são:

a) Leilões Abertos: todos os lances são publicamente observados. Por exemplo: leilão inglês ou de preço ascendente, que começa com um preço baixo e as ofertas têm de aumentar; e, leilão holandês ou de preço descendente, no qual o lance começa com um preço alto que diminui progressivamente até que um dos licitantes pare o processo adquirindo o objeto;

b) Leilões Selados: todas as ofertas são submetidas ao leiloeiro através de um envelope lacrado, ou seja, cada licitante envia sua proposta sem o conhecimento das propostas feitas pelos outros. Por exemplo: leilão de primeiro preço e leilão de segundo preço, mais conhecido como leilão de Vickrey;

c) Leilões de Preços Uniformes: os licitantes vencedores pagam o mesmo preço, que corresponde ao preço mínimo que permite que todas as mercadorias sejam vendidas ou ao preço que gera a maior lucratividade aceita pelo leiloeiro;

d) Leilões de Múltiplos Preços: os licitantes pagam seu lance individual.

e) Leilões de Valor Privado: o valor do objeto a ser licitado é diferente para cada um dos participantes;

f) Leilões de Valor Comum: apesar dos participantes apresentarem estimativas diferentes antes do leilão, depois que a incerteza é removida, 
ou seja, depois de ocorrer o leilão, o valor ex-post do item é comum a todos os participantes.

Nesse estudo, um gerador de energia renovável interessado em distribuir seus RECs investirá na plataforma, a fim de obter um retorno com a venda dos RECs no mercado digital, que será feita através de leilões ingleses, ou seja, de preços ascendentes. Nos três modelos propostos, esses leilões de venda são trimestrais e possuem uma duração de dois anos. 


\section{3 Certificados de Energia Renovável}

Em diversos países, a estrutura de geração, transmissão e distribuição de energia torna impossível rastrear fisicamente a fonte de energia até seu ponto de consumo. Nesses casos, a energia elétrica de uma fonte renovável simplesmente é injetada no sistema de distribuição, misturando-se com outros elétrons de outras fontes (renováveis ou não), e é entregue através do distribuidor local para empresas ou residências por meio dos postes e fios. Logo, nesse esquema, nem o distribuidor local de energia pode informar sobre a origem desses elétrons.

Desta forma, apesar de algumas empresas investirem em uma usina própria para gerar energia renovável e outras, por meio de políticas de compras sustentáveis, darem preferência às fontes renováveis em compras de energia no mercado livre, elas normalmente utilizam um "mix" de fontes renováveis e não renováveis para a sua transmissão. Por isso, mesmo que as empresas produzam ou comprem energia limpa, essas ações não conseguem ser contabilizadas em termos de redução de emissão.

Os Certificados de Energia Renovável, conhecidos mundialmente como RECs, surgiram como uma solução para o problema de rastreabilidade de atributos ambientais de energia. Os RECs se originaram através de um sistema de certificação global, o I-REC (International REC Standard), que possibilita, de forma prática e confiável, comprovar a origem da energia consumida, bem como o comércio de certificados.

A plataforma I-REC permite ao consumidor ter a escolha do tipo de energia renovável que deseja, através de RECs gerados por usinas eólicas, de biomassa e solares. Ao adquirir um REC, que comprova que $1 \mathrm{MWh}$ foi injetado no sistema a partir de uma fonte de geração de energia renovável, o consumidor se apropria daquela energia que foi injetada no sistema e a plataforma passa a garantir que aquele REC não será usado por mais ninguém.

Além disso, a plataforma I-REC permite que usinas ganhem o direito de transacionar os certificados e se tornarem emissores de RECs. Para isso, essas 
usinas deverão passar por um ciclo de certificação antes de aderir ao código IREC. Inicialmente, a usina deve apresentar informações detalhadas sobre o seu empreendimento e passar por uma auditoria documental pelo emissor local, no qual são verificados se a fonte de energia é renovável, se a energia é legalmente instalada, se a energia é interligada no grid do sistema nacional de energia e se existe duplo beneficiário do REC. Com todos os documentos avaliados e aceitos pela auditoria, a usina pode começar a emitir, vender e transferir os RECs para os compradores por meio da plataforma I-REC, em que estarão registradas na condição de participante.

Os benefícios dos RECs são diversos. Para as organizações emissoras de certificados, o principal benefício é que o registro no I-REC se torna uma forma de obter uma receita adicional, que é um incentivo direto para que o produtor continue investindo em geração de energia renovável.

Já, para quem adquire os RECs, o principal benefício é a comprovação da origem da eletricidade consumida e a correspondente redução de emissão de gases de efeito estufa. Atualmente, existem mercados que só aceitam esse tipo de crédito, como o de projetos que buscam a certificação Leadership in Energy and Environmental Design (LEED), cuja finalidade é a construção de prédios verdes.

Outra vantagem ao obter RECs é que eles podem ser utilizados para o reporte das emissões indiretas pelo consumo de energia no Programa Brasileiro GHG Protocol, que objetiva o registro e publicação de Inventários de Emissões de Gases do Efeito Estufa. Ademais, a compra de RECs possibilita melhorar o Índice de Sustentabilidade Empresarial (ISE), que é utilizado pelo Novo Mercado (B3) para acompanhar o desempenho das empresas preocupadas com as melhores práticas de sustentabilidade.

Portanto, os RECs trazem o reconhecimento a quem consome energia limpa e apoia a preservação dos recursos naturais, a sustentabilidade e o desenvolvimento de energia renovável. Além disso, os certificados viabilizam o cumprimento de metas de sustentabilidade de muitas organizações e possibilitam a melhora nos indicadores para programas de reporte como o Carbon Disclosure Program (CDP), o Índice de Sustentabilidade Empresarial (ISE) e o Down Jones Sustainability Index (DJSI). 


\section{4 \\ Modelagem}

Este capítulo descreve as estratégias empíricas que serviram de base para o desenvolvimento dos três protocolos autônomos de emissão e venda de RECs. Apesar de serem bastante diferentes, os três modelos preveem: um investimento inicial, que permitirá a entrada do gerador de energia renovável na plataforma e a criação de novos tokens; e, leilões de venda trimestrais, em que uma quantidade de tokens será disponibilizada ao mercado, como mostra a Figura 1:

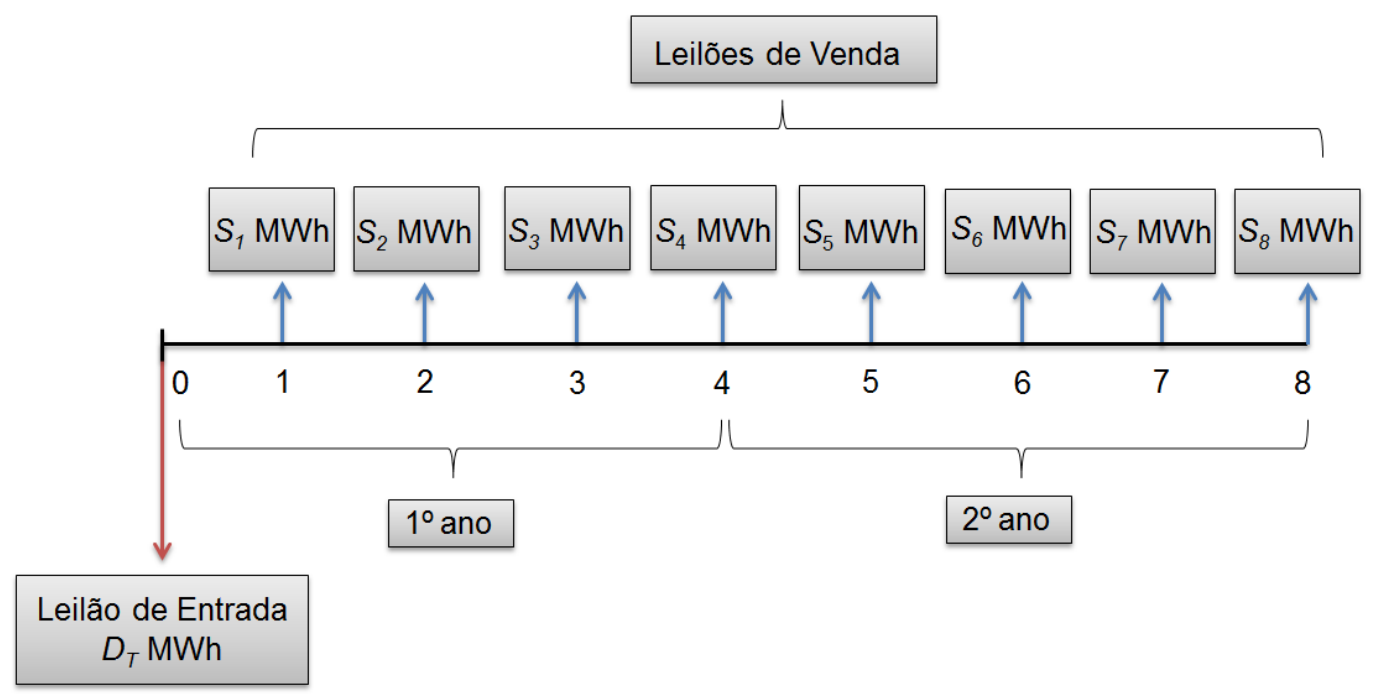

Figura 1 - Esquema Geral de Leilões de Venda

Note que o investimento do gerador de energia renovável acontece na data zero e que a oferta de RECs ao mercado $\left(S_{t}\right)$ ocorrerá durante oito trimestres (ou dois anos). Além disso, os três modelos consideram que o gerador tem a flexibilidade de investir agora ou daqui a um ano para entrar na plataforma, ou seja, o gerador tem uma opção real europeia de adiar por um ano o seu investimento para ter o direito de emitir e vender RECs, sendo responsabilidade dele avaliar qual a melhor tomada de decisão em cada modelo. 


\section{1.}

\section{Primeiro Modelo}

No primeiro modelo, a ideia é ofertar os RECs de forma a reproduzir uma stable coin, que é uma criptomoeda cuja principal finalidade é minimizar a volatilidade dos preços. A motivação para o desenvolvimento deste modelo originou-se do fato da série histórica de transações diárias de RECs ser extremamente volátil.

Diante disso, consideramos que a quantidade de RECs a ser ofertada $\left(S_{t}\right)$ nos leilões de venda é estritamente igual à demanda esperada por RECs para o mesmo período $\left(D_{t}\right)$. Além disso, assumimos que o preço unitário do token é fixo em todos os trimestres, seguindo o conceito de uma stable coin.

Nesse sentido, estabelecemos que a demanda trimestral por RECs segue a função apresentada na equação (1). Essa modelagem foi inspirada no artigo seminal de Grenadier (1996), que propõe que o preço de um ativo segue uma função (convexa) inversa da demanda sujeita a choques contínuos estocásticos. Como o preço do token é fixo neste modelo, alteramos a ideia original da modelagem, colocando a demanda por RECs em evidência nesta função. É importante ressaltar que, com essa modificação, passamos a trabalhar com uma função côncava.

$$
D_{t}=\max \left[\left(3-\frac{P}{C_{t}}\right) \times D_{0}, 0\right]
$$

Onde:

- $D_{t}$ é a demanda no trimestre $t$;

- $\quad P$ é o preço fixo unitário do REC (R/REC);

- $D_{0}$ é a demanda inicial;

- $C_{t}$ representa um choque de demanda multiplicativo, que segue um Movimento Geométrico Browniano (MGB), como mostra a equação (2).

$$
d C_{t}=\mu C_{t} d t+\sigma C_{t} d z_{t}
$$


Onde:

- $d C_{t}$ é a variação incremental do choque no intervalo de tempo $d t$;

- $\mu$ representa o drift, isto é, a taxa de crescimento esperada da demanda por RECs;

- $\sigma$ é a volatilidade da demanda por RECs;

- $d z_{t}=\varepsilon \sqrt{d t}$ representa o incremento padrão de Wiener, onde $\varepsilon \approx N(0,1)$.

Deve-se notar que os valores de $\mu$ e $\sigma$ são constantes. Assim, para qualquer valor inicial $C_{0}$, a equação tem a solução analítica apresentada na equação (3).

$$
C_{t}=C_{0} \exp \left[\left(\mu-\sigma^{2} / 2\right) t+\sigma \varepsilon \sqrt{\Delta t}\right]
$$

Onde:

- $C_{t}$ é uma variável aleatória com uma distribuição log-normal, que apresenta um valor esperado de $E\left[C_{t}\right]=C_{0} \times e^{\mu t}$ e variância de $\operatorname{Var}\left[C_{t}\right]=e^{2 \mu t} C_{0}^{2}\left(e^{\sigma^{2} t}-1\right)$.

Após estimar a demanda total por RECs, podemos calcular o investimento que o gerador de energia renovável deverá fazer para entrar na plataforma, definido na equação (4).

$$
I=\lambda \times \sum_{t=1}^{8} E\left[D_{t}\right]
$$

Onde:

- I é o investimento;

- $E\left[D_{t}\right]$ representa o valor esperado da demanda no trimestre $t$.

- $\lambda$ é o custo marginal unitário fixo de entrada na plataforma em R\$/REC.

Por outro lado, a receita auferida ao gerador em cada trimestre $\left(R_{t}\right)$ dependerá tanto da oferta de RECs no mesmo período $\left(S_{t}\right)$ quanto do preço unitário do REC $(P)$, como mostra a equação (5). 


$$
R_{t}=P \times S_{t}
$$

Mas, definimos anteriormente que a oferta de RECs é estritamente igual à demanda por RECs. Logo, a equação (5) também pode ser escrita como a equação (6):

$$
R_{t}=P \times D_{t}
$$

Portanto, o Valor Presente Líquido (VPL) de participar desse protocolo para o gerador é definido pela equação (6):

$$
V P L=-I+\int_{t=1}^{n} E\left[R_{t}\right] e^{-k t} d t
$$

Onde:

- $E\left[R_{t}\right]$ é o valor esperado das receitas futuras auferidas ao gerador;

- $n$ representa a quantidade total de trimestres;

- $k$ é o custo médio ponderado de capital (WACC).

Como o método tradicional de FCD não consegue capturar a incerteza e a flexibilidade gerencial presentes neste caso, adotamos o modelo discreto de árvore binomial proposto por Cox, Ross e Rubinstein (1979) (CRR), onde o valor da incerteza $(V)$ em cada período de tempo pode assumir dois valores, $V u$ e $V d$, com probabilidades $p$ e 1-p, respectivamente, como mostra a Figura 2. 


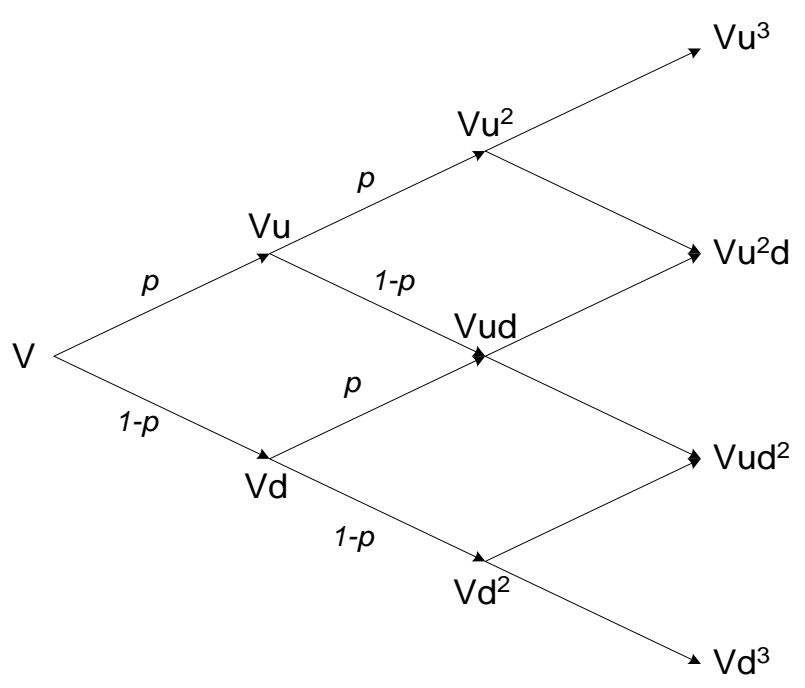

Figura 2 - Estrutura Binomial CRR

Para que se aproxime de um Movimento Geométrico Browniano (MGB), o modelo CRR estabelece que os parâmetros da árvore binomial devam seguir as expressões apresentadas na equação (8):

$$
u=e^{\sigma \sqrt{d t}}, \quad d=\frac{1}{u} \quad \text { e } \quad p=\frac{1+r_{f}-d}{u-d}
$$

Onde:

- $\sigma$ é a volatilidade adotada no processo estocástico da incerteza, que nesse caso é o choque $\left(C_{t}\right)$;

- $\quad r_{f}$ é a taxa livre de risco.

Ressalta-se que este modelo de precificação de opções exige a utilização da medida neutra ao risco, que pode ser encontrada deduzindo o prêmio de risco da taxa de retorno do ativo e, em seguida, descontando-se os fluxos de caixa à taxa livre de risco. Dessa forma, o processo neutro ao risco do choque é definido pela equação (9).

$$
d C_{t}^{R}=\left(\mu-\zeta_{C}\right) C_{t}^{R} d t+\sigma C_{t}^{R} d z_{t}
$$


Onde:

- $\zeta_{C}$ representa o prêmio de risco do choque;

- $\mu$ é a taxa de retorno do choque;

- $d C_{t}^{R}$ é a variação incremental do choque neutro ao risco no intervalo de tempo $d t$.

Conforme abordado por Freitas e Brandão (2009), o prêmio de risco de ativos de mercado pode ser observado diretamente ou pode ser determinado através do CAPM (Capital Asset Pricing Model), onde $\mu=r_{f}+\zeta$ e $\zeta=\beta\left(E\left[R_{M}\right]-r_{f}\right)$. Por outro lado, o prêmio de risco de ativos de mercado incompleto, como é o caso da incerteza deste primeiro modelo $\left(C_{t}\right)$, só pode ser calculado através de métodos indiretos.

Neste trabalho, para avaliarmos o prêmio de risco do choque, consideramos o fato de que o valor esperado dos ganhos na avaliação neutra ao risco, sem consideração das eventuais opções existentes, deve ser estritamente igual ao valor esperado dos ganhos na avaliação estática tradicional, como mostra a equação (10):

$$
\int_{t=1}^{n} f\left(C_{t}\right) e^{-\mu t} d t=\int_{t=1}^{n} f\left(C_{t}^{R}\right) e^{-\left(\mu-\zeta_{C}\right) t} d t
$$

Onde:

- $f($.$) representa os fluxos de caixa do gerador.$

A partir disso, assumindo que as demais variáveis da equação (9) são conhecidas, o valor do prêmio de risco pode ser determinado por equivalência.

Note que, até o momento, definimos apenas como a incerteza deverá ser tratada neste modelo. Para incorporarmos a flexibilidade, que é dada pela opção do gerador adiar por um ano ou não o seu investimento, assumimos algumas premissas: se o gerador optar por não adiar, ele seguirá o esquema padrão de leilões apresentado na Figura 1; mas, se ele optar por adiar, o seu investimento passa a acontecer no quarto trimestre $\left(I_{A}\right)$ e a assumir o valor apresentado na equação (11). 


$$
I_{A}=\left(\lambda \times \sum_{t=5}^{12} E\left[D_{t}\right]\right) \times(1+k)^{4}
$$

Além disso, tanto o valor da incerteza quanto a quantidade de RECs a ser ofertada corresponderão aos valores estimados para o quinto trimestre em diante, como mostra a Figura 3.

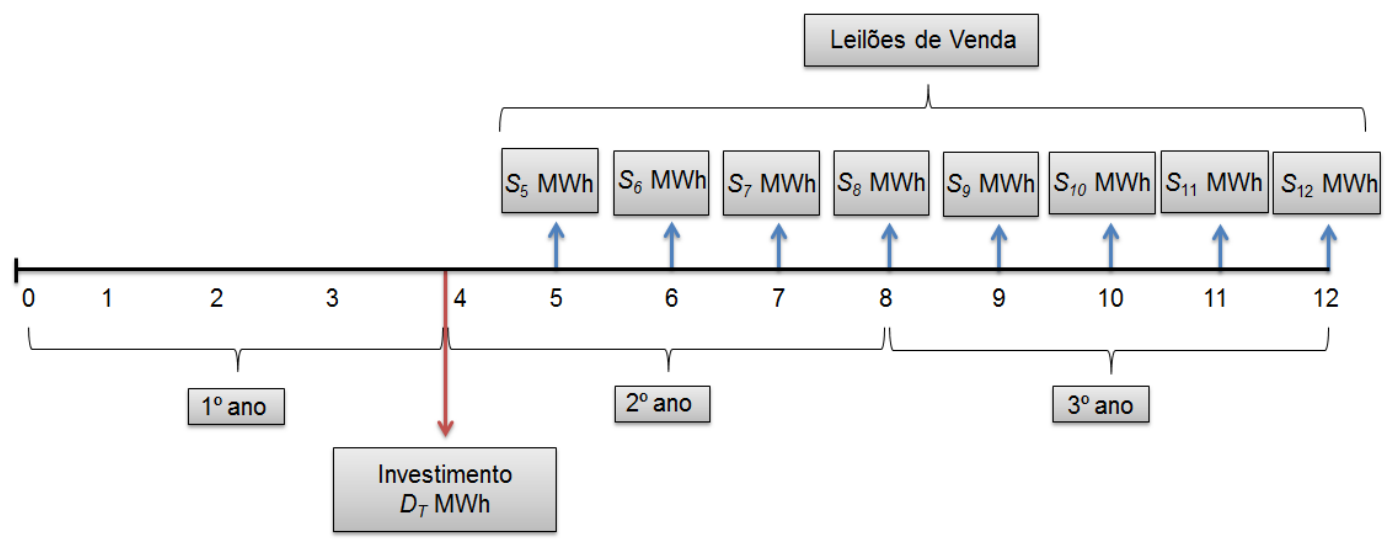

Figura 3 - Adiamento do Investimento no Primeiro Modelo

Após avaliar o VPL considerando tanto a incerteza quanto a flexibilidade, espera-se que o gerador de energia renovável possa determinar se é melhor investir agora ou daqui a um ano neste primeiro modelo. Aqui, a intenção é analisar a tomada de decisão do gerador sob incerteza diante de um protocolo autônomo baseado no conceito de uma stable coin.

\section{2.}

\section{Segundo Modelo}

No segundo modelo, também consideramos que a quantidade de RECs a ser ofertada $\left(S_{t}\right)$ nos leilões de venda é estritamente igual à demanda esperada por RECs para o mesmo período $\left(D_{t}\right)$. Contudo, nesse caso, a demanda por RECs é determinística e possui um crescimento percentual a cada trimestre, como mostra a equação (10).

$$
D_{t}=D_{0}(1+\alpha)^{t}
$$


Onde:

- $D_{t}$ é a demanda no trimestre $t$;

- $D_{0}$ é a demanda inicial;

- $\alpha$ é a taxa de crescimento da demanda a cada trimestre.

Apesar da demanda ser determinística, o preço unitário do REC varia a cada trimestre e é definido como uma função de demanda inversa sujeita a choques estocásticos contínuos, como mostra a equação (13). Note que, neste caso, estamos utilizando exatamente o modelo proposto por Grenadier (1996).

$$
P_{t}=\left[3-\frac{D_{t}}{D_{0}}\right] \times C_{t}
$$

Onde:

- $P_{t}$ é o preço unitário do REC no trimestre $t$;

- $C_{t}$ representa um choque de demanda multiplicativo, que segue um Movimento Geométrico Browniano (MGB), assim como no primeiro modelo.

A partir disso, verificamos que o investimento que o gerador de energia renovável deve fazer para entrar nesta plataforma é definido pela equação (14):

$$
I=\lambda \times \sum_{t=1}^{8} D_{t}
$$

Onde:

- I é o investimento;

- $\lambda$ é o custo marginal unitário de entrada na plataforma em R $\$ / R E C$.

E, a receita auferida ao gerador por trimestre $\left(R_{t}\right)$ é determinada pela equação (15):

$$
R_{t}=P_{t} \times S_{t}
$$


Onde:

- $S_{t}$ é a oferta de RECs em cada trimestre $t$.

Como a oferta de RECs é igual à demanda por RECs, a expressão da receita também pode ser definida através da equação (16):

$$
R_{t}=P_{t} \times D_{t}
$$

Diante disso, assim como no primeiro modelo, podemos determinar o VPL do gerador, através da equação (6); e, modelar a incerteza $\left(C_{t}\right)$, através do modelo CRR de árvore binomial, utilizando o mesmo conceito de neutralidade ao risco apresentado anteriormente.

Para capturarmos a flexibilidade, assumimos outras premissas: se o gerador optar por não adiar, ele seguirá o esquema padrão de leilões apresentado na Figura 1; por outro lado, se o gerador optar por adiar, o seu investimento passa a acontecer no quarto trimestre $\left(I_{A}\right)$ e passa a assumir o valor definido na equação (17).

$$
I_{A}=\left(\lambda \times \sum_{t=1}^{8} D_{t}\right) \times(1+k)^{4}
$$

E, como a demanda por RECs nos primeiros quatro trimestres não é realizada, consideramos que elas se repetirão nos próximos quatro trimestres, promovendo um deslocamento de um ano no modelo, como mostra a Figura 4. 


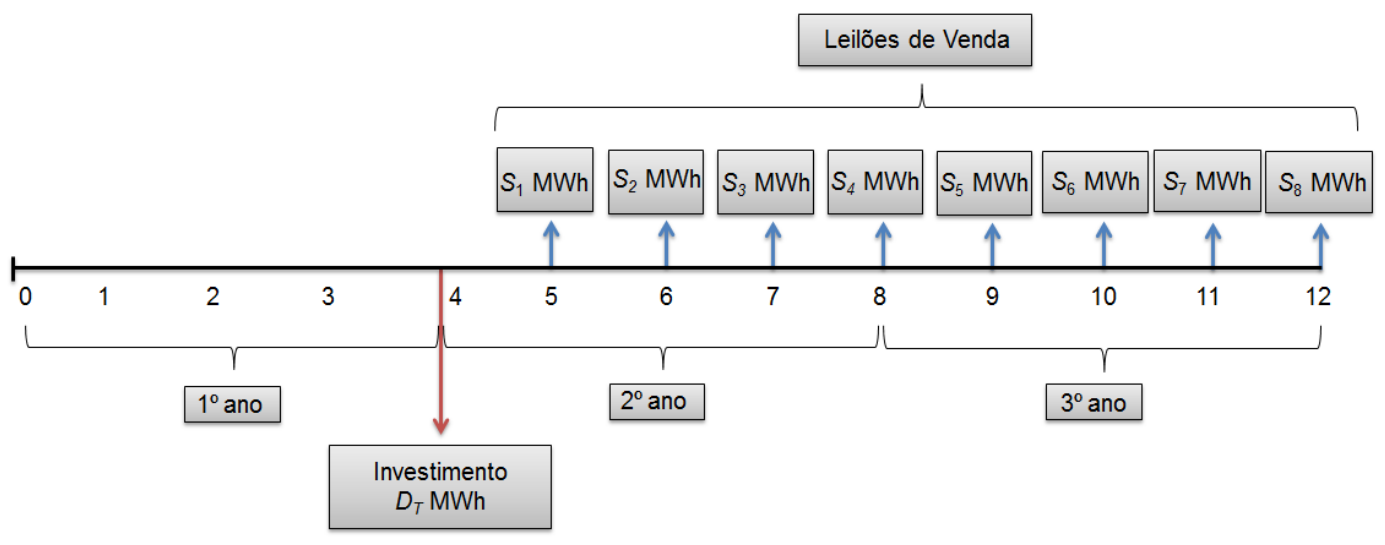

Figura 4 - Adiamento do Investimento no Segundo Modelo

Ressalta-se que, neste modelo, quando o gerador adia a sua decisão de investimento, apenas a oferta de RECs se desloca por um ano (Figura 4). Já, a incerteza, que é definida pelo choque multiplicativo da demanda $\left(C_{t}\right)$, continuará seguindo um MGB desde o primeiro trimestre.

\section{3.}

\section{Terceiro Modelo}

No terceiro modelo, seguimos a mesma lógica de que a quantidade de RECs a ser ofertada $\left(S_{t}\right)$ nos leilões de venda é estritamente igual à demanda esperada por RECs para o mesmo período $\left(D_{t}\right)$. Porém, neste caso, a demanda por RECs não é determinística, é uma variável estocástica que segue um MGB, como mostra a equação (18).

$$
d D_{t}=\mu D_{t} d t+\sigma D_{t} d z_{t}
$$

Onde:

- $d D_{t}$ é a variação incremental da demanda no intervalo de tempo $d t$;

- $\mu$ representa o drift, isto é, a taxa de crescimento esperada da demanda por RECs;

- $\sigma$ é a volatilidade da demanda por RECs;

- $d z_{t}=\varepsilon \sqrt{d t}$ representa o incremento padrão de Wiener, onde $\varepsilon \approx N(0,1)$. 
Uma das diferenças deste modelo para o anterior é que a incerteza não está mais no choque $\left(C_{t}\right)$ e sim na própria demanda $\left(D_{t}\right)$. Logo, neste caso, alteramos a ideia original proposta por Grenadier (1996) para que o preço unitário do REC varie a cada trimestre, seguindo uma função de demanda inversa sujeita a choques determinísticos, como mostra a equação (19). Ressalta-se que esta função, diferente da desenvolvida por Grenadier (1996), é côncava, visto que a incerteza não está mais no choque.

$$
P_{t}=\max \left[\left(3-\frac{D_{t}}{D_{0}}\right) \times C_{t}, 0\right]
$$

Onde:

- $P_{t}$ é o preço unitário do REC no trimestre $t$;

- $D_{0}$ é a demanda inicial;

- $C_{t}$ é o choque no trimestre $t$, que é definido pela equação (20).

$$
C_{t}=C_{0}(1+\alpha)^{t}
$$

Onde:

- $C_{0}$ representa o choque inicial;

- $\quad \alpha$ é a taxa de crescimento do choque a cada trimestre.

A partir disso, podemos avaliar o investimento que o gerador de energia renovável deve fazer para entrar nesta plataforma, através da equação (4), como no primeiro modelo. Por outro lado, para calcular a receita auferida ao mesmo por trimestre utilizamos a equação (14), definida no segundo modelo.

A outra diferença, a principal, entre o segundo e terceiro modelos é que o objetivo deste é maximizar o lucro do gerador de energia renovável, através da escolha da demanda ótima. Nesse sentido, como a função da receita auferida ao gerador é côncava, podemos aplicar a Condição de Primeira Ordem (CPO), como mostra a equação (21). 


$$
\frac{\partial R_{t}}{\partial D_{t}}=0
$$

Após definirmos a demanda ótima e inclui-la como uma barreira absorvente no processo estocástico da demanda, calculamos o VPL de participar do terceiro protocolo para o gerador, através da equação (6), assim como nos outros dois modelos. Para modelarmos a incerteza, que neste caso é a demanda por RECs, também utilizamos o modelo CRR de árvore binomial.

Contudo, como a incerteza deriva da demanda neste modelo, devemos utilizar o processo neutro ao risco definido na equação (22):

$$
d D_{t}^{R}=\left(\mu-\zeta_{D}\right) D_{t}^{R} d t+\sigma D_{t}^{R} d z_{t}
$$

Onde:

- $\zeta_{D}$ representa o prêmio de risco da demanda;

- $\mu$ é a taxa de retorno da demanda;

- $d D_{t}^{R}$ é a variação incremental do choque neutro ao risco no intervalo de tempo $d t$.

Assim como nos outros modelos, consideramos a igualdade entre os valores esperados dos ganhos das avaliações tradicional e neutra ao risco para calcular o prêmio de risco. Porém, neste caso, os fluxos de caixa são funções da demanda, como mostra a equação (23):

$$
\int_{t=1}^{n} f\left(D_{t}\right) e^{-\mu t} d t=\int_{t=1}^{n} f\left(D_{t}^{R}\right) e^{-\left(\mu-\zeta_{D}\right) t} d t
$$

Onde:

- $f($.$) representa os fluxos de caixa do gerador.$

Por fim, para inserirmos a flexibilidade ao modelo, assumimos as mesmas premissas definidas no primeiro modelo. 


\section{5 Exemplo Numérico e Resultados}

Este capítulo verifica a validade dos três modelos propostos e expõe os resultados encontrados em cada um deles com o objetivo de analisar a tomada de decisão do investidor sob incerteza. Para isso, primeiro, definimos os valores dos inputs comuns aos três modelos, como mostra a Tabela 1. É importante ressaltar que a demanda inicial por RECs, o seu crescimento percentual a cada trimestre, a volatilidade e o drift foram determinados com base no histórico de transações diárias de RECs entre 2014 e 2018, fornecido pelo Instituto Totum (2018).

\begin{tabular}{lcc} 
Parâmetros & Valores Trimestrais & Valores Anuais \\
\hline Choque Inicial $\left(C_{0}\right)$ & 1,00 & 1,00 \\
Demanda Inicial $\left(D_{0}\right)$ & $15.000 \mathrm{MWh}$ & $15.000 \mathrm{MWh}$ \\
Taxa de Crescimento $(\alpha)$ & $5,00 \%$ & $21,55 \%$ \\
Taxa de Desconto $(k)$ & $6,00 \%$ & $26,25 \%$ \\
Taxa Livre de Risco $(r)$ & $1,30 \%$ & $5,30 \%$ \\
Volatilidade $(\sigma)$ & $30,00 \%$ & $185,61 \%$ \\
Drift $(\mu)$ & $5,00 \%$ & $21,55 \%$ \\
Custo Marginal Unitário $(\lambda)$ & $\mathrm{R} \$ 1,50 / \mathrm{REC}$ & $\mathrm{R} \$ 1,50 / \mathrm{REC}$ \\
\hline
\end{tabular}

Tabela 1 - Parâmetros Comuns aos Três Modelos

\section{1. Análise dos Resultados do Primeiro Modelo}

Com os valores do choque inicial e da demanda inicial determinados na Tabela 1 e assumindo que o preço de venda unitário do token é fixo e igual a $\mathrm{R} \$$ 2,00 em todos os trimestres, podemos determinar a demanda por RECs em cada trimestre e, consequentemente, o investimento que o gerador deve fazer no instante inicial, bem como a receita que será auferida a ele nos oito trimestres.

Para isso, precisamos modelar a incerteza deste primeiro modelo, que é dada pelo choque de demanda $\left(C_{t}\right)$. Nesse sentido, primeiro, calculamos o prêmio de risco $\left(\zeta_{C}=3,56 \%\right.$ a.t. ou $15,02 \%$ a.a. $)$ através de métodos numéricos, considerando a equivalência matemática entre os VPs (Valores Presentes) da 
avaliação tradicional estática e da avaliação neutra ao risco apresentada na Tabela 2.

\begin{tabular}{ccc} 
Trimestre & Fluxo de Caixa Tradicional & Fluxo de Caixa Neutro ao Risco \\
\hline 1 & $\mathrm{R} \$ 27.559,38$ & $\mathrm{R} \$ 25.422,99$ \\
2 & $\mathrm{R} \$ 29.704,47$ & $\mathrm{R} \$ 26.360,51$ \\
3 & $\mathrm{R} \$ 29.247,81$ & $\mathrm{R} \$ 24.816,48$ \\
4 & $\mathrm{R} \$ 30.726,43$ & $\mathrm{R} \$ 25.343,70$ \\
5 & $\mathrm{R} \$ 30.526,00$ & $\mathrm{R} \$ 24.319,86$ \\
6 & $\mathrm{R} \$ 31.685,46$ & $\mathrm{R} \$ 24.666,45$ \\
7 & $\mathrm{R} \$ 31.558,50$ & $\mathrm{R} \$ 23.852,36$ \\
8 & $\mathrm{R} \$ 32.525,74$ & $\mathrm{R} \$ 24.098,11$ \\
\hline $\mathbf{V P}$ & $\mathbf{R} \$ \mathbf{1 8 7 . 8 7 4 , 5 8}$ & $\mathbf{R} \mathbf{1 8 7 . 8 7 4 , 5 8}$ \\
\hline
\end{tabular}

Tabela 2 - Equivalência entre Valores Presentes no Primeiro Modelo

Após isso, calculamos os fatores de upside e downside da árvore binomial ( $u$ $=1,35$ e $d=0,74)$. E, a partir desses valores, determinamos as probabilidades neutras ao risco do modelo ( $p=44,92 \%$ e $1-p=55,08 \%)$. Utilizando o software DPL, modelamos a incerteza para os próximos oito trimestres, incorporando a receita auferida ao gerador como o fluxo de caixa do modelo, como mostra a Figura A.1.

A partir da modelagem da incerteza, verificamos que o valor da demanda esperada para os próximos dois anos é igual a 121.767 MWh e que o investimento do gerador nesta plataforma é igual a $\mathrm{R} \$ 182.650,34$. Ademais, através dessa árvore binomial, encontramos que o VPL de participar desse esquema de emissão e venda de RECs para o gerador é igual a $\mathrm{R} \$ 5.224,23$.

Contudo, note que ainda não consideramos a flexibilidade neste cálculo, que é dada pela opção do gerador adiar ou não o seu investimento. Para incluí-la no modelo, desenvolvemos a árvore binomial apresentada na Figura A.2.

Neste caso, a demanda esperada por RECs passa a ser igual a $129.539 \mathrm{MWh}$ e, consequentemente, o investimento do gerador passa a assumir o valor de $I_{A}=$ $\mathrm{R} \$$ 245.310,64. Além disso, considerando a opção de adiar por um ano o investimento, encontramos que o VPL de participar desse esquema de emissão e venda de RECs para o gerador é igual a $R \$ 40.044,68$. Nesse sentido, a opção de adiamento promoveu um crescimento de aproximadamente $666,52 \%$ no VPL para 
o gerador. Note que essa opção é extremamente valiosa para o gerador, devido à alta volatilidade da demanda por RECs.

Para obtermos as probabilidades de exercício da opção (Figura 5), descontamos a árvore binomial à taxa ajustada ao risco $(k)$. Como é padrão na literatura, não utilizamos a análise de probabilidade neutra ao risco para avaliar a política de decisão do gerador, visto que estas não representam as probabilidades reais do modelo.

Investe

Investe1
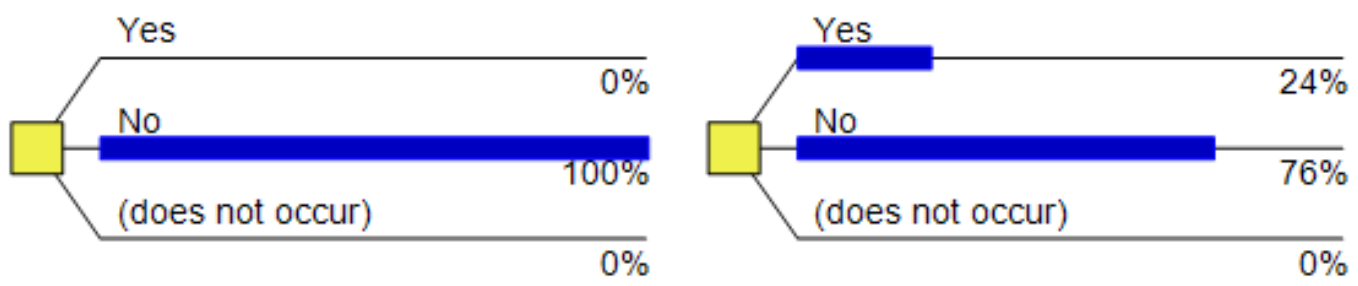

Figura 5 - Política de Decisão no Primeiro Modelo

Observe que o gerador nunca deve investir de imediato no primeiro modelo. Porém, em 24\% dos casos, ele deve investir no segundo momento e, consequentemente, em $76 \%$, ele não deve investir nunca nesta plataforma. Esse resultado é esperado devido ao alto grau de incerteza provocado pela volatilidade da demanda por RECs.

\subsection{1.}

\section{Análises de Sensibilidade}

Conforme abordado anteriormente, a volatilidade da demanda por RECs $(\sigma)$ é extremamente alta e é um dos parâmetros que torna valiosa a opção do gerador adiar seu investimento. Nesse sentido, apesar da volatilidade ter sido calculada com base em dados reais sobre transações de RECs no mercado, é interessante realizar uma análise de sensibilidade para verificar o impacto das variações deste parâmetro no VPL do gerador, como mostra a Figura 6. 


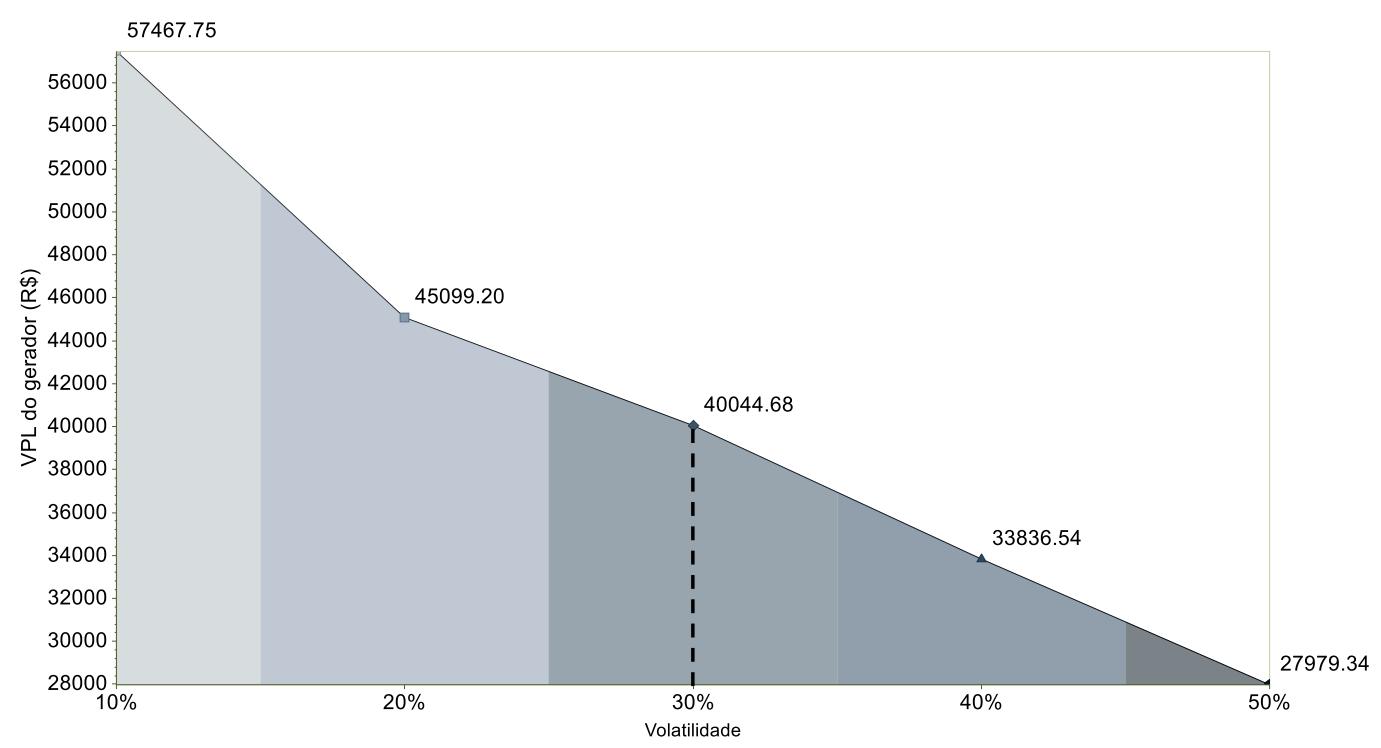

Figura 6 - Análise de Sensibilidade da Volatilidade no Primeiro Modelo

Para isso, consideramos que a volatilidade pode assumir valores entre $10,00 \%$ e 50,00\% e, como podemos observar, o VPL do gerador diminui à medida que a volatilidade assume valores maiores. Esse resultado não é esperado, visto que na maioria dos casos de opções reais analisamos funções convexas, que seguem a regra de que quanto maior a incerteza, maior o valor da opção, como mostra a Figura 7.

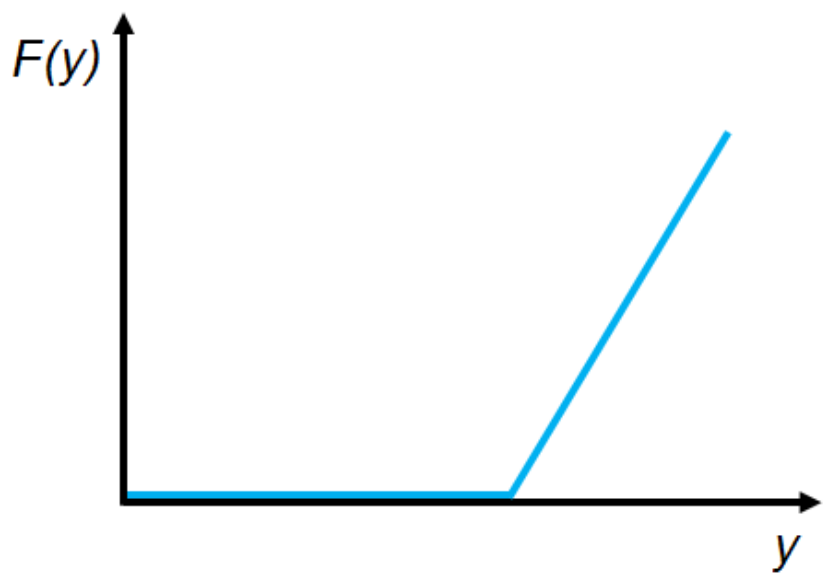

\section{Figura 7 - Opção Real Tradicional}

Nota: $y$ representa a incerteza e $F(y)$ representa uma função convexa de $y$. 
Contudo, o resultado da sensibilidade da volatilidade é válido, visto que a função do VPL no primeiro modelo é côncava e possui comportamento contrário ao descrito acima. Ou seja, neste caso, é pertinente afirmar que quanto maior a incerteza, menor o valor da opção.

Outro parâmetro importante para realizarmos a análise de sensibilidade é o custo marginal unitário de entrada na plataforma $(\lambda)$. Apesar de ter sido estimado com base no valor atual de mercado do REC, acreditamos que é interessante verificar como a variação deste parâmetro pode impactar o VPL do gerador, como mostra a Figura 8.

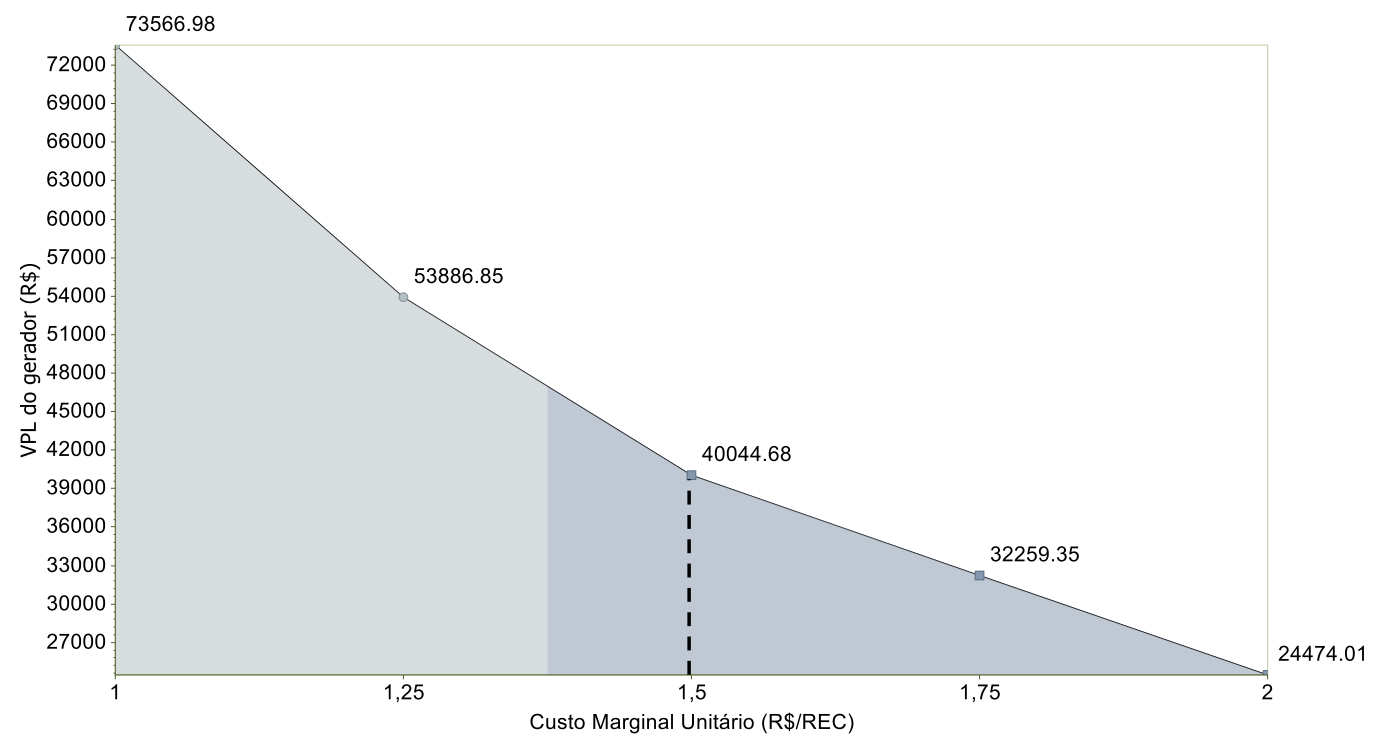

Figura 8 - Análise de Sensibilidade do Custo Marginal Unitário de Entrada no Primeiro Modelo

Nesta análise, consideramos que o custo marginal unitário pode assumir valores entre $R \$ 1,00$ e $R \$ 2,00$. Como este custo impacta diretamente o valor do investimento para entrar na plataforma, quanto maior for este parâmetro, menor será o VPL do gerador. Note que o VPL do gerador aumenta em $83,71 \%$ quando o valor do parâmetro diminui em 50,00\% e que o VPL do gerador diminui $61,12 \%$ quando o valor do parâmetro aumenta em 50,00\%. 


\section{2.}

\section{Análise dos Resultados do Segundo Modelo}

A partir da definição da demanda inicial e do seu crescimento percentual na Tabela 1, podemos determinar os valores esperados da demanda em cada trimestre para os próximos dois anos, como mostra a Tabela 3.

\begin{tabular}{cc}
$\boldsymbol{t}$ & Demanda $\left(\boldsymbol{D}_{\boldsymbol{t}}\right)$ \\
\hline 1 & 15.750 \\
2 & 16.538 \\
3 & 17.364 \\
4 & 18.233 \\
5 & 19.144 \\
6 & 20.101 \\
7 & 21.107 \\
8 & 22.162 \\
\hline Total $\left(\boldsymbol{D}_{\boldsymbol{T}}\right)$ & $\mathbf{1 5 0 . 3 9 8} \mathbf{M W h}$ \\
\hline
\end{tabular}

\section{Tabela 3 - Projeção da Demanda por Trimestre}

Como a demanda total por RECs para os próximos dois anos é igual a 150.398 MWh, o investimento do gerador de energia renovável será igual a R\$ 225.597,70. A partir disso, podemos modelar o choque de demanda multiplicativo $\left(C_{t}\right)$, que representa a incerteza neste segundo modelo e que define a receita auferida ao gerador.

Nesse sentido, utilizamos os valores de upside e downside da árvore binomial ( $u=1,35$ e $d=0,74)$ e calculamos por métodos numéricos o valor do prêmio de risco ( $\zeta_{C}=4,66 \%$ a.t. ou $19,98 \%$ a.a. $)$, considerando a equivalência matemática entre os VPs apresentada na Tabela 4. 


\begin{tabular}{ccc} 
Trimestre & Fluxo de Caixa Tradicional & Fluxo de Caixa Neutro ao Risco \\
\hline 1 & $\mathrm{R} \$ 32.248,13$ & $\mathrm{R} \$ 30.818,26$ \\
2 & $\mathrm{R} \$ 34.596,35$ & $\mathrm{R} \$ 31.596,39$ \\
3 & $\mathrm{R} \$ 37.034,38$ & $\mathrm{R} \$ 32.323,31$ \\
4 & $\mathrm{R} \$ 39.547,65$ & $\mathrm{R} \$ 32.986,41$ \\
5 & $\mathrm{R} \$ 42.116,34$ & $\mathrm{R} \$ 33.571,32$ \\
6 & $\mathrm{R} \$ 44.714,25$ & $\mathrm{R} \$ 34.061,78$ \\
7 & $\mathrm{R} \$ 47.307,48$ & $\mathrm{R} \$ 34.439,35$ \\
8 & $\mathrm{R} \$ 49.852,86$ & $\mathrm{R} \$ 34.683,16$ \\
\hline VP & $\mathbf{R} \$ \mathbf{2 3 . 7 6 9 , 9 4}$ & $\mathbf{R} \mathbf{2 3 . 7 6 9 , 9 4}$ \\
\hline
\end{tabular}

\section{Tabela 4 - Equivalência entre Valores Presentes no Segundo Modelo}

e, consequentemente, as probabilidades neutras ao risco $(p=43,12 \%$ e $1-p=$ $56,88 \%$ ). A partir disso, utilizando o software DPL, modelamos a incerteza para os próximos oito trimestres, incorporando a receita auferida ao gerador como o fluxo de caixa do modelo, como mostra a Figura A.3.

Através dessa árvore binomial, encontramos que o VPL de participar do segundo protocolo para o gerador é igual a $\mathrm{R} \$ 23.769,94$. Neste cálculo, não consideramos a opção do gerador adiar por um ano o seu investimento. Para incluirmos esta flexibilidade gerencial ao modelo, precisamos redesenhar a árvore binomial, como mostra a Figura A.4. Ademais, ressalta-se que caso o gerador escolha adiar, o investimento para entrada na plataforma passa a ser igual a $I_{A}=$ $\mathrm{R} \$ 284.811,89$.

Agora, considerando a opção de adiar o investimento, encontramos que o VPL do gerador passa a ser igual a R \$ 60.992,70. Logo, a opção promoveu um crescimento de aproximadamente $156,60 \%$ no seu VPL.

Para avaliarmos a política de decisão do gerador de energia renovável, descontamos a árvore binomial pela taxa ajustada ao risco $(k)$, assim como no primeiro modelo. A Figura 9 apresenta as probabilidades reais de exercício da opção: 
Investe

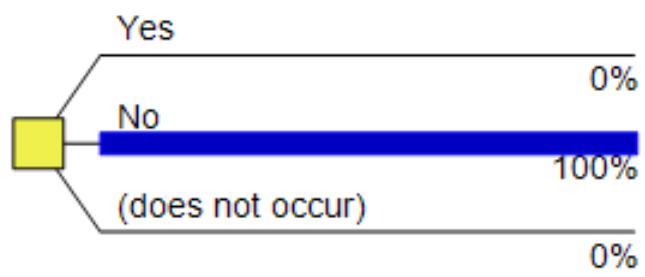

Investe1

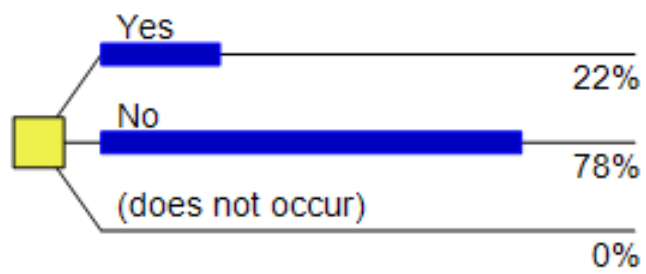

\section{Figura 9 - Política de Decisão no Segundo Modelo}

Note que, assim como no primeiro modelo, o gerador nunca deve investir de imediato nesta plataforma. Contudo, o resultado mostra que, em $22 \%$ dos casos, ele deve investir no segundo momento e que, em $78 \%$, ele não deve investir nunca.

\subsection{1.}

\section{Análises de Sensibilidade}

Assim como no primeiro modelo, realizamos análises de sensibilidade sobre dois parâmetros: a volatilidade e o custo marginal unitário de entrada no protocolo. Primeiro, consideramos que a volatilidade pode assumir valores entre $10,00 \%$ e $50,00 \%$ e avaliamos o impacto disso no VPL do gerador, como mostra a Figura 10. 


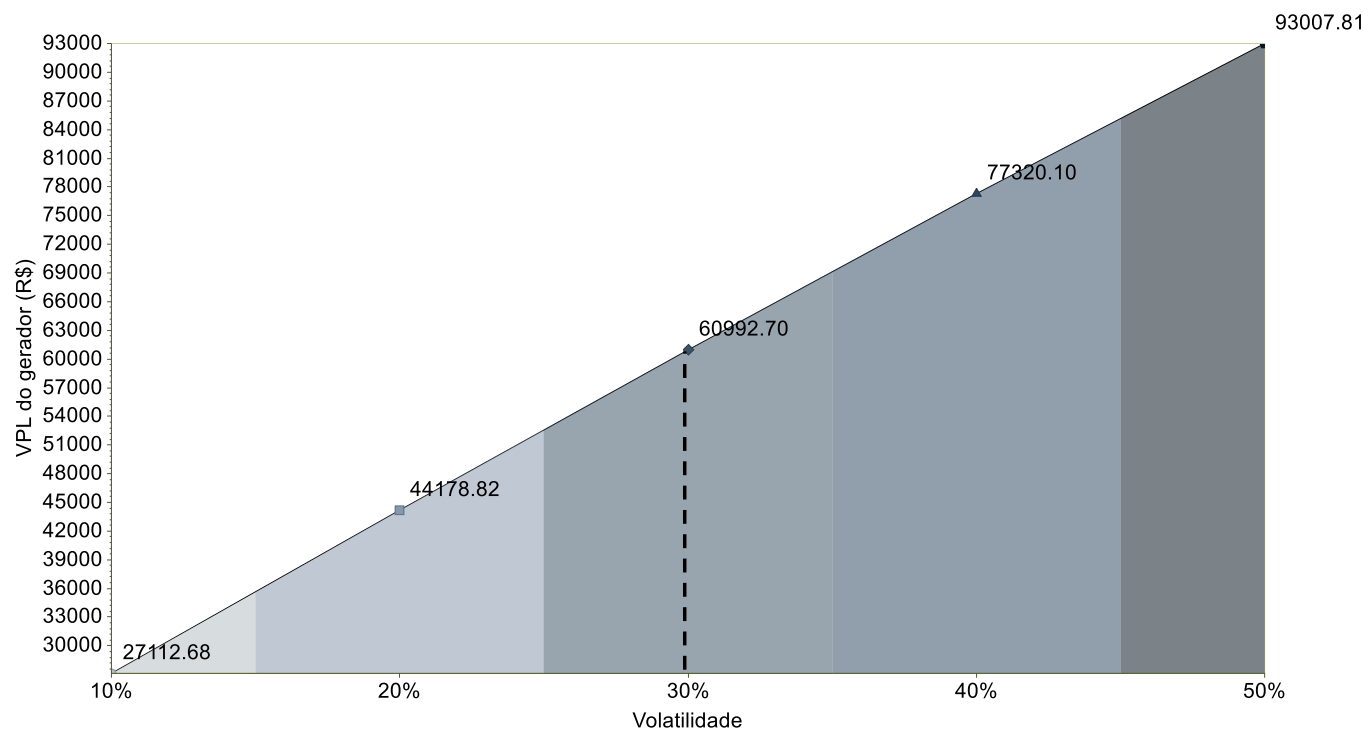

Figura 10 - Análise de Sensibilidade da Volatilidade no Segundo Modelo

Podemos observar que o VPL do gerador pode assumir valores entre R $\$$ 27.112,68 e R\$93.007,81. Logo, o VPL aumenta à medida que a volatilidade assume valores maiores. Esse resultado é esperado porque o VPL, no segundo modelo, é uma função convexa.

Na próxima análise de sensibilidade, avaliamos o impacto no VPL a partir de variações no custo marginal unitário de entrada na plataforma. Para isso, assumimos que esse parâmetro pode assumir valores entre $R$ \$ 1,00 e R $\$ 2,00$, como mostra a Figura 11. 


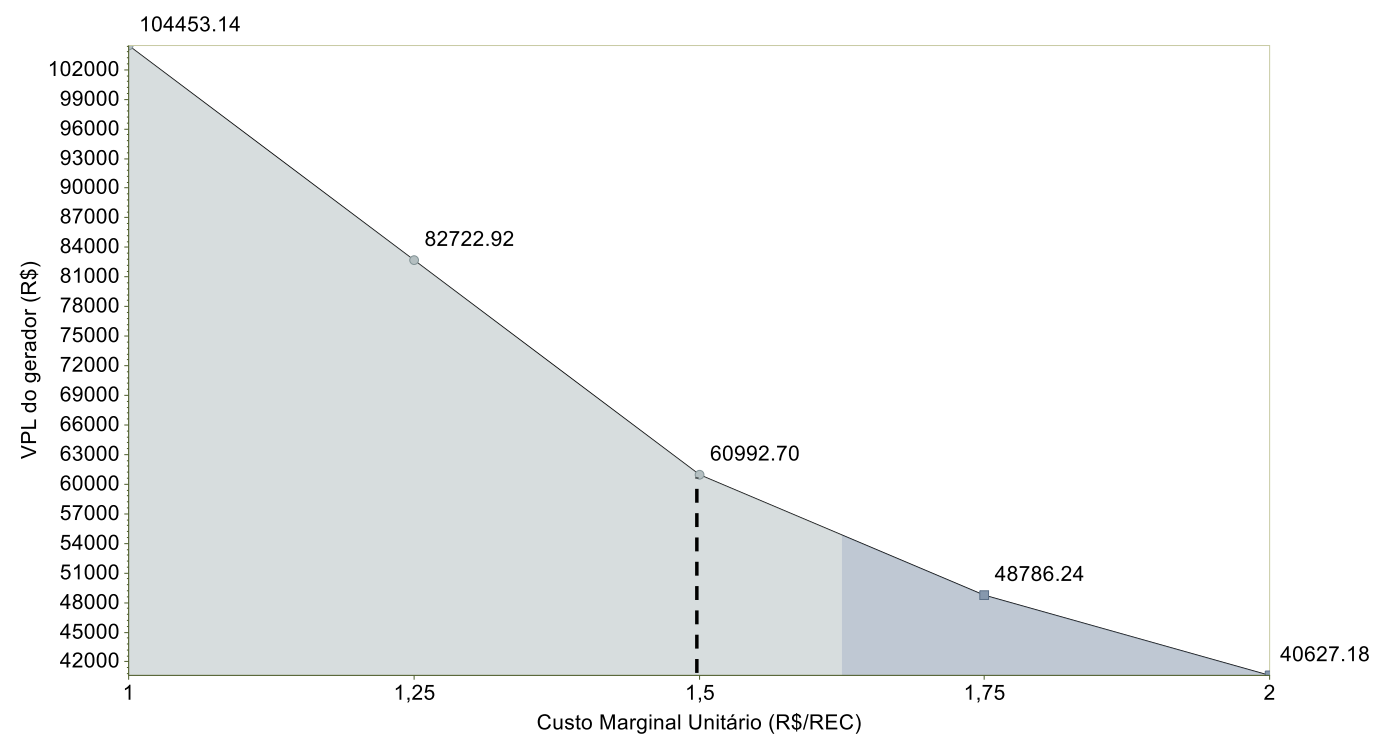

Figura 11 - Análise de Sensibilidade do Custo Marginal Unitário de Entrada no Segundo Modelo

Observe que o VPL do gerador, neste caso, varia entre $\mathrm{R} \$ 40.627,18$ e $\mathrm{R} \$$ 104.453,14 e que à medida que o custo marginal unitário aumenta, o VPL do gerador diminui. Ademais, note que um aumento de 50,00\% no valor deste parâmetro provoca uma redução de 66,61\% no VPL do gerador e que, em contrapartida, uma redução de $50,00 \%$ provoca um aumento de $71,26 \%$ no VPL do gerador.

\section{3.}

Análise dos Resultados do Terceiro Modelo

Com os valores do choque inicial $\left(C_{0}\right)$ e da taxa de crescimento $(\alpha)$ apresentados na Tabela 1, podemos determinar o valor do choque em cada trimestre para os próximos três anos, como mostra a Tabela 5: 


\begin{tabular}{cc}
$\boldsymbol{t}$ & Choque $\left(\boldsymbol{C}_{\boldsymbol{t}}\right)$ \\
\hline 1 & 1,05 \\
2 & 1,10 \\
3 & 1,16 \\
4 & 1,22 \\
5 & 1,28 \\
6 & 1,34 \\
7 & 1,41 \\
8 & 1,48 \\
9 & 1,55 \\
10 & 1,63 \\
11 & 1,71 \\
12 & 1,80 \\
\hline
\end{tabular}

\section{Tabela 5 - Projeção do Choque por Trimestre}

Neste caso, o investimento na plataforma é dado pelo custo marginal unitário de entrada multiplicado pela demanda esperada para os primeiros oito trimestres, apresentada na Tabela 6.

\section{Demanda Esperada $E\left[D_{t}\right]$}

\begin{tabular}{cc}
$\boldsymbol{t}$ & Demanda Esperada $E\left[\boldsymbol{D}_{\boldsymbol{t}}\right]$ \\
\hline 1 & 15.750 \\
2 & 16.538 \\
3 & 17.364 \\
4 & 18.233 \\
5 & 19.144 \\
6 & 20.101 \\
7 & 21.107 \\
8 & 22.162 \\
\hline Total & $\mathbf{1 5 0 . 3 9 8} \mathbf{M W h}$ \\
\hline
\end{tabular}

\section{Tabela 6 - Demanda Esperada no Caso Base}

Ao definirmos o total da demanda esperada por RECs para os próximos dois anos, encontramos que o valor do investimento do gerador é igual a R\$ 225.597,70. Após isso, utilizamos os valores de upside e downside da árvore binomial $(u=1,35$ e $d=0,74)$; calculamos o prêmio de risco $\left(\zeta_{D}=10,16 \%\right.$ a.t. ou $47,26 \%$ a.a.) através de métodos numéricos, respeitando a equivalência entre os VPs apresentada na Tabela 7; e, determinamos as probabilidades neutras ao risco $(p=34,09 \%$ e $1-p=65,91 \%)$. 


\begin{tabular}{ccc} 
Trimestre & Fluxo de Caixa Tradicional & Fluxo de Caixa Neutro ao Risco \\
\hline 1 & $\mathrm{R} \$ 30.787,93$ & $\mathrm{R} \$ 29.333,39$ \\
2 & $\mathrm{R} \$ 31.515,70$ & $\mathrm{R} \$ 28.851,59$ \\
3 & $\mathrm{R} \$ 32.748,41$ & $\mathrm{R} \$ 28.589,31$ \\
4 & $\mathrm{R} \$ 33.777,36$ & $\mathrm{R} \$ 28.257,22$ \\
5 & $\mathrm{R} \$ 35.227,11$ & $\mathrm{R} \$ 28.083,99$ \\
6 & $\mathrm{R} \$ 36.472,08$ & $\mathrm{R} \$ 27.820,02$ \\
7 & $\mathrm{R} \$ 38.110,85$ & $\mathrm{R} \$ 27.685,85$ \\
8 & $\mathrm{R} \$ 39.550,69$ & $\mathrm{R} \$ 27.461,15$ \\
\hline VP & $-\mathbf{R} \$ \mathbf{1 2 . 0 5 6 , 9 8}$ & $-\mathbf{R} \$ \mathbf{1 2 . 0 5 6 , 9 8}$ \\
\hline
\end{tabular}

Tabela 7 - Equivalência entre Valores Presentes no Terceiro Modelo

Para modelarmos a demanda por RECs, que é a incerteza neste modelo, utilizamos o software DPL e incorporamos a receita auferida ao gerador como o fluxo de caixa do modelo, como mostra a Figura A.5. Através desse modelo, encontramos que o VPL de participar do terceiro protocolo para o gerador é negativo e igual a - R\$ 12.056,97.

Note que não consideramos a opção do gerador adiar por um ano o seu investimento. Para incluirmos a flexibilidade ao modelo, primeiro, consideramos que o investimento do gerador, no caso de adiamento, aumenta para $I_{A}=\mathrm{R} \$$ 346.190,64, visto que a demanda esperada passa a assumir os valores apresentados na Tabela 8; e, posteriormente, projetamos a árvore apresentada na Figura A.6.

\begin{tabular}{cc}
$\boldsymbol{t}$ & Demanda Esperada $E\left[\boldsymbol{D}_{t}\right]$ \\
\hline 5 & 19.144 \\
6 & 20.101 \\
7 & 21.107 \\
8 & 22.162 \\
9 & 23.270 \\
10 & 24.433 \\
11 & 25.655 \\
12 & 26.938 \\
\hline Total & $\mathbf{1 8 2 . 8 1 0 ~ M W h}$ \\
\hline
\end{tabular}

Tabela 8 - Demanda Esperada no Caso de Adiamento 
Ao considerarmos a opção do gerador adiar por um ano seu investimento, o seu VPL passa a ser igual a $\mathrm{R} \$ 5.357,52$. Nesse caso, a opção de adiamento promoveu um crescimento de $144,44 \%$ no VPL do gerador.

Assim como nos outros dois modelos, descontamos a árvore binomial à taxa ajustada ao risco $(k)$ para gerar as probabilidades reais do modelo. A política de decisão do gerador neste protocolo é apresentada na Figura 12.

Investe

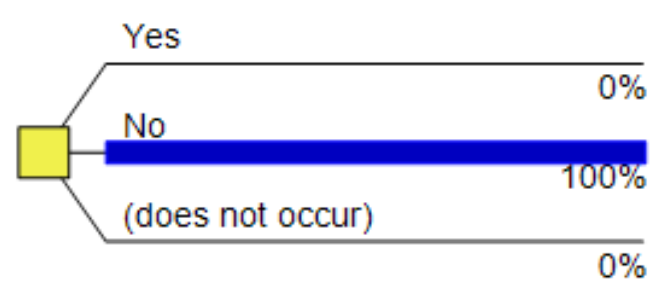

Investe1

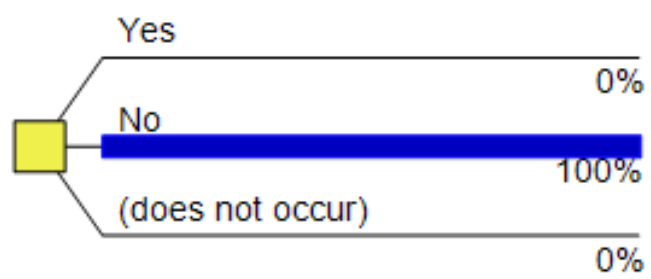

\section{Figura 12 - Política de Decisão no Terceiro Modelo}

Estes valores de probabilidade permitem afirmar que o gerador de energia renovável nunca deve investir no terceiro modelo proposto neste estudo.

\subsection{1.}

\section{Análises de Sensibilidade}

Assim como nos outros dois modelos, realizamos análises de sensibilidade sobre a volatilidade e o custo marginal de entrada no protocolo. A Figura 13 apresenta a primeira análise de sensibilidade: 


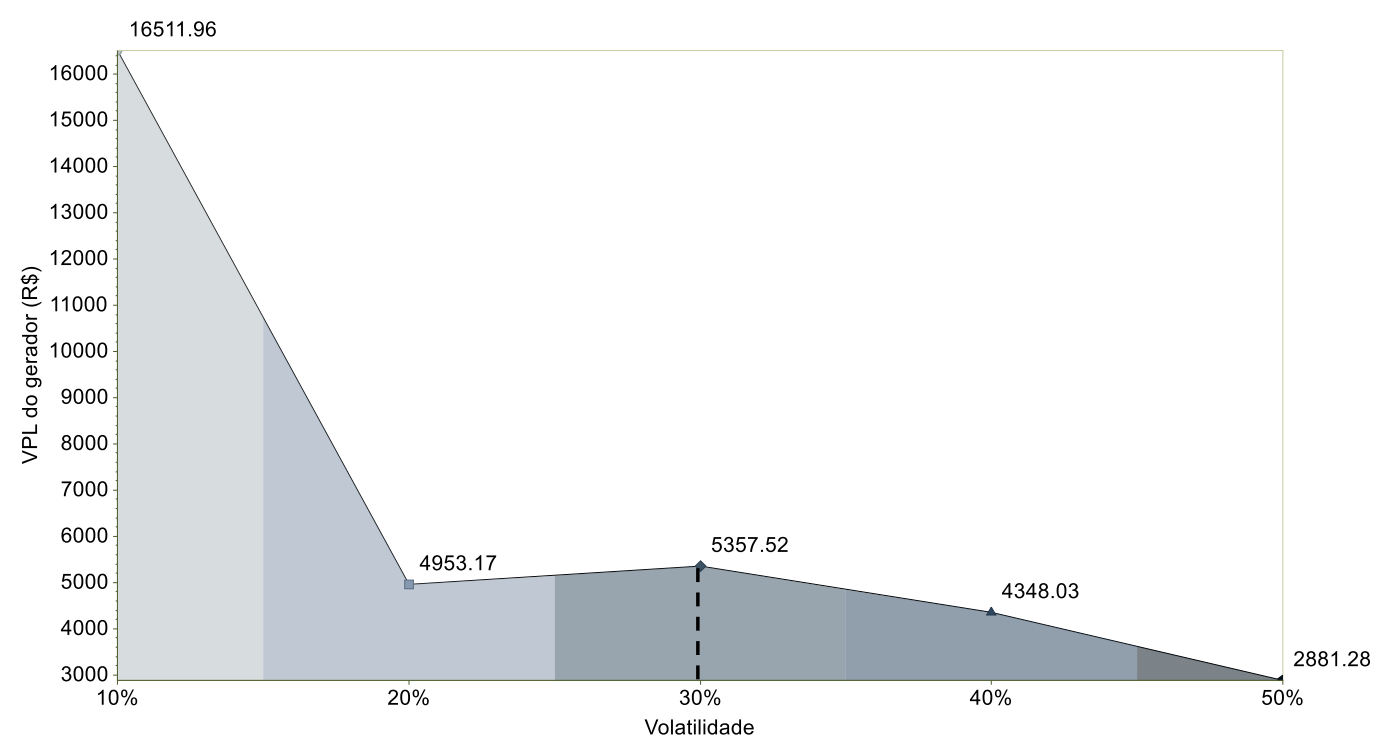

Figura 13 - Análise de Sensibilidade da Volatilidade no Terceiro Modelo

Considerando que a volatilidade pode assumir valores entre 10,00\% e $50,00 \%$, avaliamos o impacto dessa variação no VPL do gerador. Note que o VPL do gerador aumenta à medida que diminuímos a volatilidade de 20,00\% para $10,00 \%$, bem como de $50,00 \%$ para $30,00 \%$. Isso é explicado pelo fato do VPL, nestes intervalos, ser uma função côncava, assim como no primeiro modelo.

É importante ressaltar, também, que a falta de monotonicidade desta curva $(20 \%<\sigma<30 \%)$ é explicada pelo fato de incorporarmos a demanda ótima, calculada a partir da CPO, como barreira absorvente no processo estocástico da incerteza. Se, a consideração desta barreira, a curva de sensibilidade passa a ser côncava para todos os valores de volatilidade analisados.

Por fim, avaliamos o impacto no VPL a partir de variações no custo marginal de entrada na plataforma. Assumimos que esse parâmetro pode assumir valores entre $\mathrm{R} \$ 1,00$ e $\mathrm{R} \$ 2,00$, como mostra a Figura 14. 


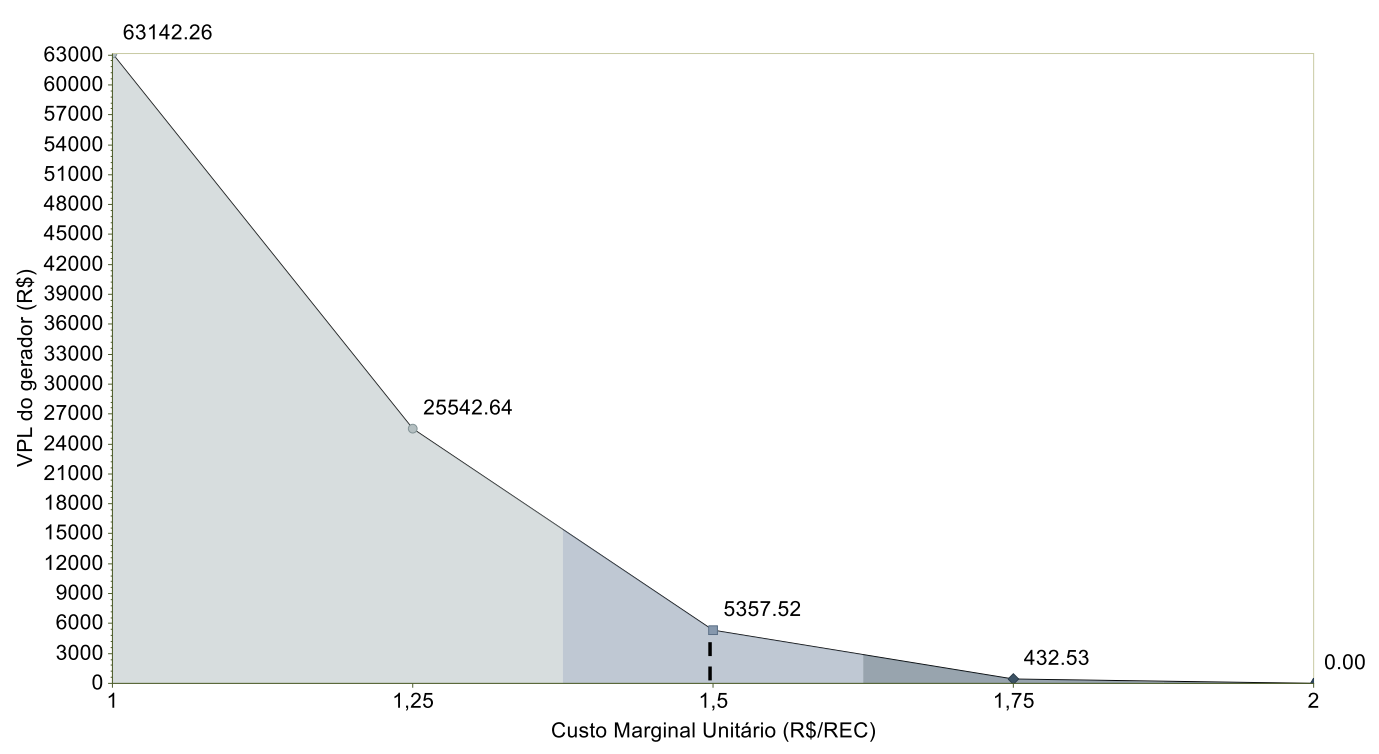

Figura 14 - Análise de Sensibilidade do Custo Marginal Unitário de Entrada no Terceiro Modelo

Nesta última análise, o VPL do gerador varia de R\$ 0,00 a R\$ 63.142,26. É importante salientar que uma redução de 50,00\% no custo marginal unitário gera um aumento de $1.078,57 \%$ no VPL do gerador. Por outro lado, um aumento de $50,00 \%$ no valor deste parâmetro gera uma redução de 100,00\% no VPL do gerador. Note que esta sensibilidade foi a que provocou impacto mais significativo no VPL do gerador.

\section{4 .}

\section{Análise Comparativa dos Modelos}

Após avaliarmos o VPL do gerador em cada modelo, podemos determinar em qual o gerador deverá investir para que sua tomada de decisão seja ótima. Ao considerarmos os parâmetros definidos na Tabela 1 e ao compararmos os VPLs de cada modelo, verificamos que o gerador deverá investir no segundo, visto que é o que fornece o maior VPL $(\mathrm{R} \$ 60.922,70)$.

Ademais, ressalta-se que mesmo considerando a análise de sensibilidade sobre o custo marginal unitário de entrada na plataforma, o segundo modelo segue sendo o modelo ótimo para o gerador, como mostra a Tabela 9: 
VPL (R\$)

\begin{tabular}{cccc} 
Custo Marginal Unitário (R\$/REC) & Modelo 1 & Modelo 2 & Modelo 3 \\
\cline { 2 - 4 } & $73.566,98$ & $\mathbf{1 0 4 . 4 5 3 , 1 4}$ & $63.142,26$ \\
1,00 & $53.886,85$ & $\mathbf{8 2 . 7 2 2 , 9 2}$ & $25.542,64$ \\
1,50 & $40.044,68$ & $\mathbf{6 0 . 9 9 2 , 7 0}$ & $5.357,52$ \\
1,75 & $32.259,35$ & $\mathbf{4 8 . 7 8 6 , 2 4}$ & 432,53 \\
2,00 & $24.474,01$ & $\mathbf{4 0 . 6 2 7 , 1 8}$ & 0,00 \\
\hline
\end{tabular}

Tabela 9 - Sensibilidade do Custo Marginal Unitário na Escolha do Modelo Ótimo

Contudo, se considerarmos a análise de sensibilidade sobre a volatilidade, o resultado pode mudar, como mostra a Tabela 10:

\begin{tabular}{cccc} 
& \multicolumn{3}{c}{ VPL (R\$) } \\
\cline { 2 - 4 } Volatilidade & Modelo 1 & Modelo 2 & Modelo 3 \\
\hline $10,00 \%$ & $\mathbf{5 7 . 4 6 7 , 7 5}$ & $27.112,68$ & $16.511,96$ \\
$20,00 \%$ & $\mathbf{4 5 . 0 9 9 , 2 0}$ & $44.178,82$ & $4.953,17$ \\
$30,00 \%$ & $40.044,68$ & $\mathbf{6 0 . 9 9 2 , 7 0}$ & $5.357,52$ \\
$40,00 \%$ & $33.836,54$ & $\mathbf{7 7 . 3 2 0 , 1 0}$ & $4.348,03$ \\
$50,00 \%$ & $27.979,34$ & $\mathbf{9 3 . 0 0 7 , 8 1}$ & $2.881,28$ \\
\hline
\end{tabular}

Tabela 10 - Sensibilidade da Volatilidade na Escolha do Modelo Ótimo

Ressalta-se que, quando a volatilidade é inferior a 20,00\%, o primeiro modelo passa a ser o modelo ótimo para o gerador. Esse resultado é explicado, principalmente, pelo fato do VPL ser uma função côncava no primeiro modelo e, em contrapartida, ser uma função convexa no segundo modelo. 


\section{6 Conclusões}

Neste trabalho, buscou-se analisar o investimento em ambiente de incerteza do gerador de energia renovável, parte interessada em ofertar RECs, em três modelos autônomos distintos de emissão e venda de tokens baseados em RECs. Nos três modelos, o gerador tem a opção de investir agora ou daqui a um ano para ter o direito de emitir RECs e ofertá-los através de leilões de venda trimestrais, que são promovidos automaticamente através do protocolo inteligente desenvolvido na blockchain.

Portanto, o principal objetivo desse trabalho é avaliar em qual dos três modelos propostos é ótimo o gerador realizar o investimento. Para isso, utilizamos a abordagem de opções reais que permitiu calcular o VPL do gerador, considerando tanto a incerteza de cada modelo quanto a flexibilidade gerencial referente à opção de adiamento.

No primeiro modelo, que segue um conceito de stable coin, o VPL do gerador é igual a R \$ 40.044,68. Já no segundo modelo, no qual o preço é uma função de demanda inversa sujeita a choques estocásticos, o VPL do gerador é R\$ 60.992,70. Por fim, no último modelo, que considera que a incerteza deriva da demanda por RECs, o VPL do gerador é R \$ 5.357,52.

Nesse sentido, podemos concluir que o gerador deve investir no segundo modelo, pois é o que fornece maior VPL. Contudo, é importante salientar que ao considerar a análise de sensibilidade da volatilidade da demanda por RECs, verificamos que se $\sigma<20,00 \%$, o modelo ótimo do ponto de vista do gerador passa a ser o primeiro.

Este trabalho contribui para o entendimento da dinâmica do desempenho de produtos digitais sob incerteza, bem como para a ampliação da literatura referente a aplicações da tecnologia blockchain no mercado de renováveis. Ademais, este estudo é relevante e original, pois analisa sob incerteza e flexibilidade o investimento do gerador de energia renovável em três DAOs distintas. Esta pesquisa também evidencia que métodos simples de precificação de opções reais 
podem auxiliar a tomada de decisão quando há incerteza e flexibilidade, fazendo com que as oportunidades de investimento sejam melhor avaliadas.

A principal limitação desta pesquisa se refere ao fato de termos poucos dados sobre as transações de RECs no mercado. O histórico fornecido pelo Instituto Totum possui informações somente para o período entre 2014 e 2018. Além disso, neste estudo consideramos somente uma incerteza em cada modelo, bem como apenas a flexibilidade gerencial de adiamento. Em trabalhos futuros, sugerimos acrescentar outras incertezas e analisar diferentes tipos de opções, como a de abandono da plataforma. 


\section{7 Referências bibliográficas}

ABRAGEL. Certificado de Energia Renovável. 2018. Disponível em: < http://www.abragel.org.br/energia-renovavel/ >. Acesso em: 26 de Agosto de 2018.

AMUNDSEN, E. S.; NESE, G. Integration of tradable green certificate markets: What can be expected? Journal of Policy Modeling, v. 31, n. 6, p. 903-922, 2009.

ARAKI, M. E.; SILVA, P. V. J. G.; Gomes, L. L.; Brandão, L. E. T. Modelo de equilíbrio para lançamento de certificados de energia renovável na blockchain. Cadernos de Gestão e Empreendedorismo, v. 6, n. 2, p. 6683, 2018. ISSN 2318-9231.

BERTOLDI, P.; HULD, T. Tradable certificates for renewable electricity and energy savings. Energy Policy, v. 34, n. 2, p. 212-222, 2006.

BLACK, F.; SCHOLES, M. The Pricing of Options and Corporate Liabilities. The Journal of Political Economy, v. 81, n. 3, p. 637-654, 1973.

BOOMSMA, T. K.; MEADE, N.; FLETEN, S.-E. Renewable energy investments under different support schemes: A real options approach. European Journal of Operational Research, v. 220, n. 1, p. 225-237, 2012.

BRITO, J.; CASTILLO, A. Bitcoin: A primer for policymakers. Policy: A Journal of Public Policy and Ideas, v. 29, n. 4, p. 3-12, 2013.

BRYANS, D. Bitcoin and Money Laundering: Mining for an Effective Solution. Indiana Law Journal, v. 89, n. 1, 2014.

BUTLER, L.; NEUHOFF, K. Comparison of feed-in tariff, quota and auction mechanisms to support wind power development. Renewable Energy, v. 33, n. 8, p. 1854-1867, 2008.

CASSADY, Ralph. Auctions and auctioneering. Univ of California Press, 1967.

CASTELLANOS, J. A. F.; COLL-MAYOR, D.; NOTHOLT, J. A. Cryptocurrency as guarantees of origin: Simulating a green certificate market with the Ethereum Blockchain. In: 2017 IEEE International Conference on Smart Energy Grid Engineering (SEGE), 2017, Oshawa, ON, Canada. Anais... Canada, 2017, p.367-372. 
COPELAND, T.; ANTIKAROV, V. Real Options: A Practitioner's Guide. Texere, New York: 2001.

COPELAND, T.; TUFANO, P. A real-world way to manage real options. Harvard Business Review, v. 82, n. 3, p. 90-99, 2004.

COX, J. C.; ROSS, S. A.; RUBINSTEIN, M. Option pricing: A simplified approach. Journal of Financial Economics, v. 7, n. 3, p. 229-263, 1979.

CURRIER, K. M. A regulatory adjustment process for the determination of the optimal percentage requirement in an electricity market with Tradable Green Certificates. Energy Policy, v. 62, p. 1053-1057, 2013.

DETERT, N.; KOTANI, K. Real options approach to renewable energy investments in Mongolia. Energy Policy, v. 56, p. 136-150, 2013.

DIAS, A. C. A. E. M.; BASTIAN-PINTO, C. D. L.; BRANDÃO, L. E. T.; Gomes, L. L. Flexibility and uncertainty in agribusiness projects: investing in a cogeneration plant. RAM. Revista de Administração Mackenzie, v. 12, n. 4, p. 105-126, 2011. ISSN 1678-6971.

DIXIT, A. K.; PINDYCK, R. S. Investment under Uncertainty. Princeton: Princeton University Press, 1994. 476.

EXTANCE, A. The future of cryptocurrencies: Bitcoin and beyond. Nature News, v. 526, n. 7571, p. 21-23, 2015.

FAGIANI, R.; BARQUÍN, J.; HAKVOORT, R. Risk-based assessment of the cost-efficiency and the effectivity of renewable energy support schemes: Certificate markets versus feed-in tariffs. Energy Policy, v. 55, p. 648-661, 2013.

FERNANDES, B.; CUNHA, J.; FERREIRA, P. The use of real options approach in energy sector investments. Renewable and Sustainable Energy Reviews, v. 15, n. 9, p. 4491-4497, 2011.

FLETEN, S.-E.; LINNERUD, K.; MOLNÁR, P.; NYGAARD, M. T. Green electricity investment timing in practice: Real options or net present value? Energy, v. 116, p. 498-506, 2016.

FONTOURA, C. F.; BRANDÃO, L. E.; GOMES, L. L. Elephant grass biorefineries: towards a cleaner Brazilian energy matrix? Journal of Cleaner Production, n. 96, p. 85-93, 2015. ISSN 0959-6526.

FRANCIS, P. Laudato Si': On Care For Our Common Home. Perspectives on Science and Christian Faith, v. 68, n. 4, p. 266-268, 2016.

FREITAS, A. S. de; BRANDÃO, L. E. Avaliação de Projetos de E-Learning através da Metodologia de Opções Reais. Revista Eletrônica de Administração, v. 15, n. 3, p. 679-701, ISSN 1413-2311. 
FRISTRUP, P. Some challenges related to introducing tradable green certificates. Energy Policy, v. 31, n. 1, p. 15-19, 2003.

GRENADIER, S. R. The Strategic Exercise of Options: Development Cascades and Overbuilding in Real Estate Markets. Journal of Finance, v. 51 , n. 5 , p. 1653-1679, 1996. ISSN 00221082. Disponível em: < http://www.jstor.org/stable/2329533 >.

HULL, J. Options, Futures and Other Derivatives. 7th Edition. New Jersey: Prentice Hall, 2009.

HURLBURT, G. F.; BOJANOVA, I. Bitcoin: Benefit or Curse? IT Professional, v. 16, n. 3, p. 10-15, 2014.

INSTITUTO TOTUM. Renewable Energy Certificates. 2018. Disponível em: < https://www.institutototum.com.br/index.php/servicos/273-i-rec >. Acesso em: 26 de Agosto de 2018.

KIM, K.; PARK, H.; KIM, H. Real options analysis for renewable energy investment decisions in developing countries. Renewable and Sustainable Energy Reviews, v. 75, p. 918-926, 2017.

KITZING, L.; JUUL, N.; DRUD, M.; BOOMSMA, T. K. A real options approach to analyse wind energy investments under different support schemes. Applied Energy, v. 188, p. 83-96, 2017.

LEE, S.-C. Using real option analysis for highly uncertain technology investments: The case of wind energy technology. Renewable and Sustainable Energy Reviews, v. 15, n. 9, p. 4443-4450, 2011.

LELLIS, M. M. Fontes alternativas de energia elétrica no contexto da matriz energética brasileira: meio ambiente, mercado e aspectos jurídicos. 2007. Masters Dissertation Engenharia da Energia, Unversidade Federal de Itajubá - UNIFEI, Itajubá.

LITTLE, E. M. Bitcoin. The Investment Lawyer, v. 21, n. 5, p. 22-26, 2014.

MAFTEI, L. Bitcoin - Between Legal and Informal. CES Working Papers, v. 6, n. 3, p. 53-59, 2014.

MAJD, S.; PINDYCK, R. S. Time to Build, Option Value, and Investment Decisions. Journal of Financial Economics, v. 18, n. 1, p. 7-27, 1987.

MARTÍNEZ-CESEÑA, E. A.; MUTALE, J. Application of an advanced real options approach for renewable energy generation projects planning. Renewable and Sustainable Energy Reviews, v. 15, n. 4, p. 2087-2094, 2011.

MCDONALD, R. L.; SIEGEL, D. R. Investment and the Valuation of Firms When There is an Option to Shut Down. International Economic Review, v. 26, n. 2, p. 331-349, 1985. 
MENEZES, F. M.; MONTEIRO, P. K. An introduction to auction theory. Oxford University Press, Inc., New York: 2005. ISBN 0199275998.

MENGELKAMP, E.; NOTHEISEN, B.; BEER, C.; DAUER, D.; WEINHARDT, C. A blockchain-based smart grid: towards sustainable local energy markets. Computer Science - Research and Development, v. 33, n. 1, p. 207-214, 2018.

MERTON, R. C. Theory of Rational Option Pricing. The Bell Journal of Economics and Management Science, v. 4, n. 1, p. 141-183, 1973.

MIHAYLOV, M.; JURADO, S.; AVELLANA, N.; VAN MOFFAERT, K.; ABRIL, I. M.; NOWÉ, A. NRGcoin: Virtual currency for trading of renewable energy in smart grids. In: 11th International Conference on the European Energy Market (EEM14), 2014, Krakow, Poland. Anais... Poland, 2014, p.1-6.

MITCHELL, C.; BAUKNECHT, D.; CONNOR, P. M. Effectiveness through risk reduction: a comparison of the renewable obligation in England and Wales and the feed-in system in Germany. Energy Policy, v. 34, n. 3, p. 297-305, 2006.

MORTHORST, P. E. The development of a green certificate market. Energy Policy, v. 28, n. 15, p. 1085-1094, 2000.

MYERS, S. Determinants of Corporate Borrowing. Journal of Financial Economics, v. 5, n. 2, p. 147-175, 1977.

NAKAMOTO, S. Bitcoin: A peer-to-peer electronic cash system. 2008. Disponível em: < https://bitcoin.org/bitcoin.pdf >. Acesso em: 26 de Agosto de 2018.

NEGURITA, O. Bitcoin - Between Legal and Financial Performance. Contemporary Readings in Law and Social Justice, v. 6, n. 1, p. 242248, 2014.

OLIVEIRA, D. L.; BRANDAO, L. E. T.; IGREJAS, R.; GOMES, L. L. Switching outputs in a bioenergy cogeneration project: A real options approach. Renewable and Sustainable Energy Reviews, v. 36, n. 0, p. 74-82, 2014. ISSN 1364-0321.

RITZENHOFEN, I.; SPINLER, S. Optimal design of feed-in-tariffs to stimulate renewable energy investments under regulatory uncertainty - A real options analysis. Energy Economics, v. 53, p. 76-89, 2016.

SMIT, H. T. J.; TRIGEORGIS, L. Real options and games: Competition, alliances and other applications of valuation and strategy. Review of Financial Economics, v. 15, n. 2, p. 95-112, 2006.

TAMÁS, M. M.; BADE SHRESTHA, S. O.; ZHOU, H. Feed-in tariff and tradable green certificate in oligopoly. Energy Policy, v. 38, n. 8, p. 40404047, 2010. 
TITMAN, S. Urban Land Prices Under Uncertainty. The American Economic Review, v. 75, n. 3, p. 505-514, 1985.

TRIANTIS, A. J. Realizing the Potential of Real Options: Does Theory Meet Practice? Journal of Applied Corporate Finance, v. 17, n. 2, p. 816, 2005.

TRIANTIS, A. J.; HODDER, J. E. Valuing Flexibility as a Complex Option. Journal of Finance, v. 45, n. 2, p. 549-565, 1990.

TRIGEORGIS, L. Real options, Managerial Flexibility and Strategy in Resources Allocation. Cambridge, Massachussets: MIT Press, 1996.

WINGATE, M.; HOLT, E. Design guide for renewable energy certificate tracking systems. Washington, DC: National Wind Coordinating Committee, 2004. 
Apêndice

Investe

$\underline{\mathrm{C} 1}$

$\underline{\mathrm{C} 2}$

$\underline{\mathrm{C} 8}$

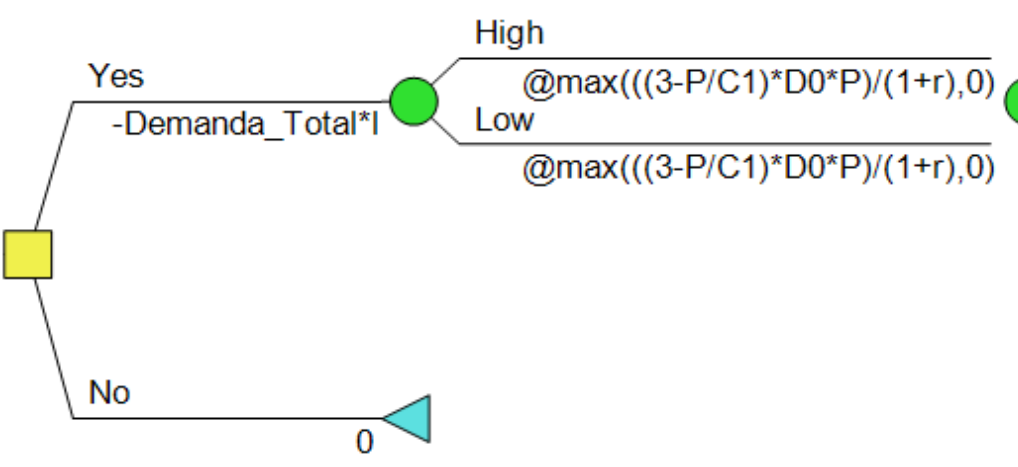

High @max $\left(\left((3-\mathrm{P} / \mathrm{C} 8)^{*} \mathrm{D} 0^{*} \mathrm{P}\right) /(1+\mathrm{r})^{\wedge} 8,0\right)$ $@ \max \left(\left((3-\mathrm{P} / \mathrm{C} 8)^{*} \mathrm{D} 0^{*} \mathrm{P}\right) /(1+\mathrm{r})^{\wedge} 8,0\right)$

Figura A.1 - Árvore Binomial do Primeiro Modelo 


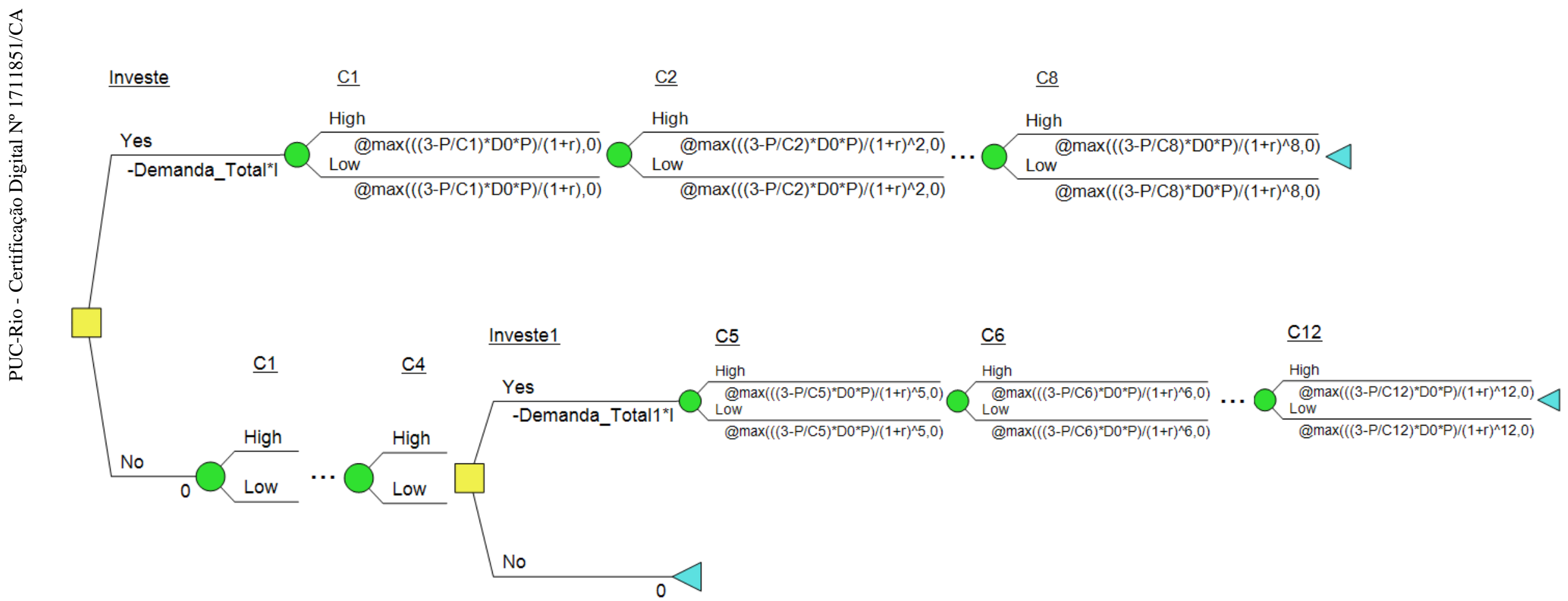

Figura A.2 - Árvore Binomial do Primeiro Modelo com Opção de Adiamento 


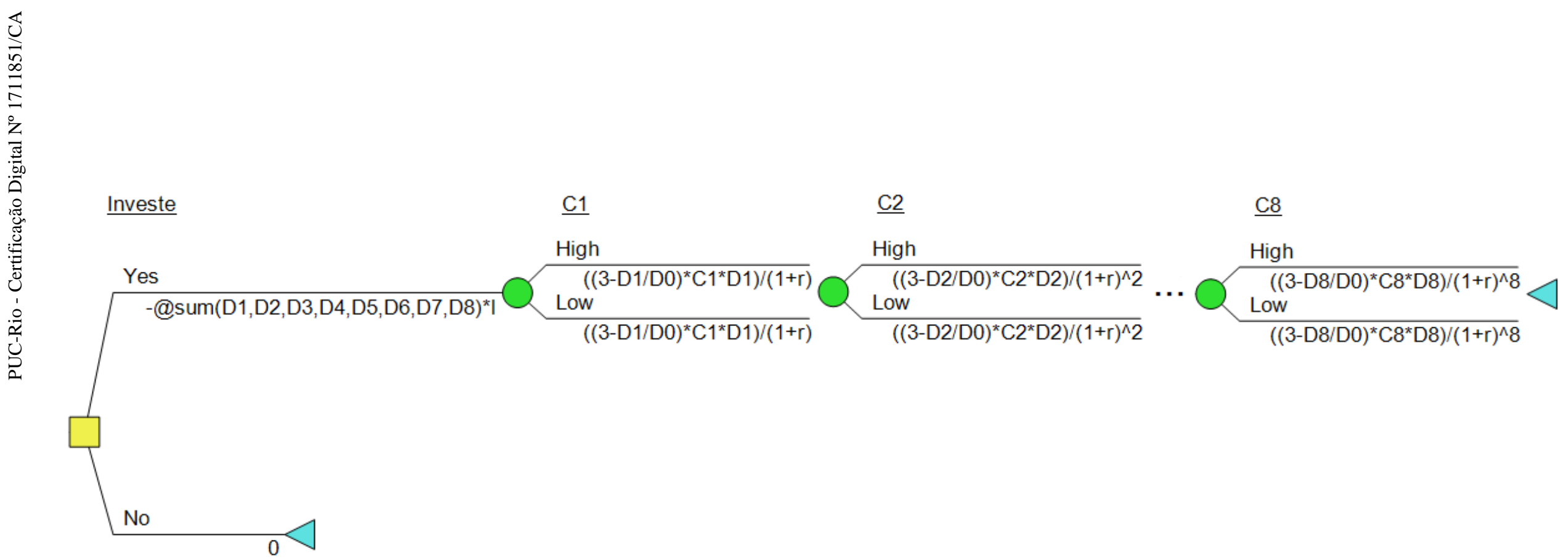

Figura A.3 - Árvore Binomial do Segundo Modelo 


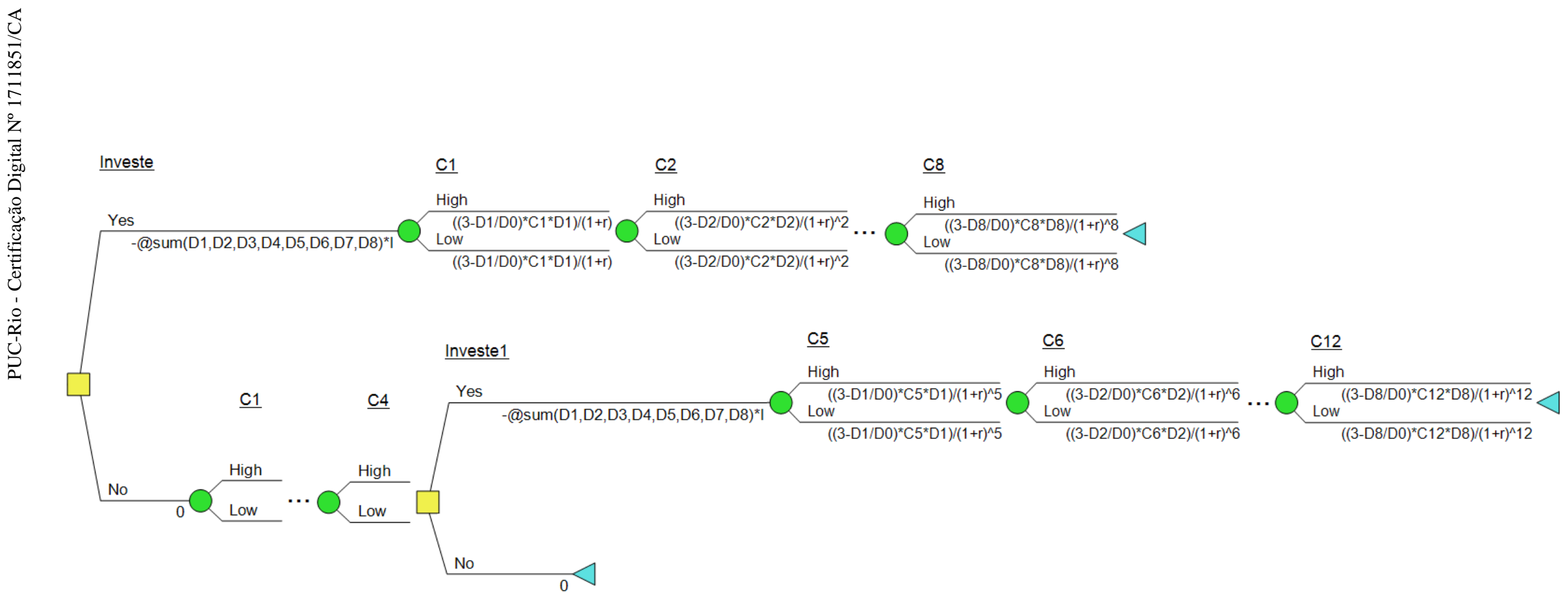

Figura A.4 - Árvore Binomial do Segundo Modelo com Opção de Adiamento 


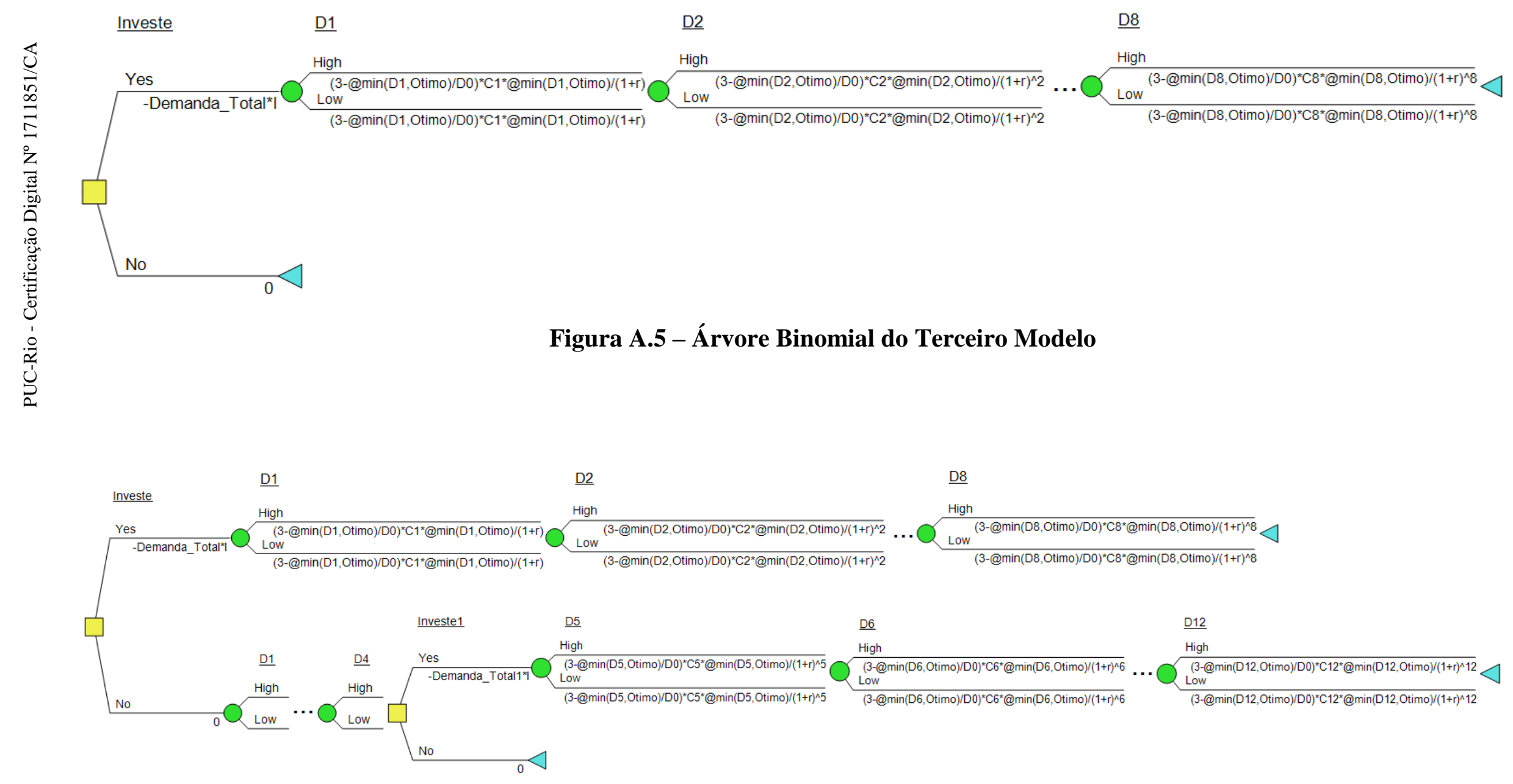

Figura A.6 - Árvore Binomial do Terceiro Modelo com Opção de Adiamento 